\title{
Functional characterization of a Penicillium chrysogenum mutanase gene induced upon co-cultivation with Bacillus subtilis
}

Ishwar Bajaj ${ }^{1,2}$, Tânia Veiga ${ }^{1,2}$, Dino van Dissel ${ }^{1,2}$, Jack T Pronk $k^{1,2}$ and Jean-Marc Daran ${ }^{1,2,3^{*}}$

\begin{abstract}
Background: Microbial gene expression is strongly influenced by environmental growth conditions. Comparison of gene expression under different conditions is frequently used for functional analysis and to unravel regulatory networks, however, gene expression responses to co-cultivation with other microorganisms, a common occurrence in nature, is rarely studied under laboratory conditions. To explore cellular responses of the antibiotic-producing fungus Penicillium chrysogenum to prokaryotes, the present study investigates its transcriptional responses during co-cultivation with Bacillus subtilis.
\end{abstract}

Results: Steady-state glucose-limited chemostats of $P$. chrysogenum grown under penillicin-non-producing conditions were inoculated with $B$. subtilis. Physiological and transcriptional responses of $P$. chrysogenum in the resulting mixed culture were monitored over 72 h. Under these conditions, B. subtilis outcompeted $P$. chrysogenum, as reflected by a three-fold increase of the $B$. subtilis population size and a two-fold reduction of the $P$. chrysogenum biomass concentration. Genes involved in the penicillin pathway and in synthesis of the penicillin precursors and side-chain were unresponsive to the presence of $B$. subtilis. Moreover, Penicillium polyketide synthase and nonribosomal peptide synthase genes were either not expressed or down-regulated. Among the highly responsive genes, two putative $a-1,3$ endoglucanase (mutanase) genes viz Pc12g07500 and Pc12g13330 were upregulated by more than 15-fold and 8-fold, respectively. Measurement of enzyme activity in the supernatant of mixed culture confirmed that the co-cultivation with $B$. subtilis induced mutanase production. Mutanase activity was neither observed in pure cultures of $P$. chrysogenum or $B$. subtilis, nor during exposure of $P$. chrysogenum to $B$. subtilis culture supernatants or heat-inactivated $B$. subtilis cells. However, mutanase production was observed in cultures of $P$. chrysogenum exposed to filter-sterilized supernatants of mixed cultures of P. chrysogenum and B. subtilis. Heterologous expression of Pc12g07500 and Pc12g13330 genes in Saccharomyces cerevisiae confirmed that Pc12g07500 encoded an active a-1,3 endoglucanase.

Conclusion: Time-course transcriptional profiling of $P$. chrysogenum revealed differentially expressed genes during co-cultivation with B. subtilis. Penicillin production was not induced under these conditions. However, induction of a newly characterized $P$. chrysogenum gene encoding a-1,3 endoglucanase may enhance the efficacy of fungal antibiotics by degrading bacterial exopolysaccharides.

Keywords: Time-course transcriptional analysis, Mixed culture, Chemostat-based transcriptomics, Mutanase, Heterologous expression, Penicillium chrysogenum, Bacillus subtilis

\footnotetext{
* Correspondence: J.G.Daran@tudelft.nl

${ }^{1}$ Department of Biotechnology, Delft University of Technology, Julianalaan

67, 2628 BC Delft, the Netherlands

${ }^{2}$ Kluyver Centre for Genomics of Industrial Fermentation, Julianalaan 67, 2628

BC Delft, the Netherlands

Full list of author information is available at the end of the article
}

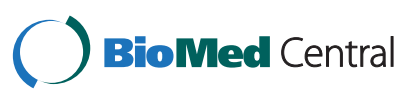

(c) 2014 Bajaj et al.; licensee BioMed Central Ltd. This is an Open Access article distributed under the terms of the Creative Commons Attribution License (http://creativecommons.org/licenses/by/2.0), which permits unrestricted use, distribution, and reproduction in any medium, provided the original work is properly credited. The Creative Commons Public Domain Dedication waiver (http://creativecommons.org/publicdomain/zero/1.0/) applies to the data made available in this article, unless otherwise stated. 


\section{Background}

Penicillium chrysogenum is widely used for industrial production of $\beta$-lactam antibiotics such as penicillins and cephalosporins. Current production strains are the result of classical strain development programmes which, over a period spanning more than six decades, has improved productivity by several orders of magnitude [1]. Throughout strain improvement, industrial and academic research has sought to understand the molecular basis and physiology of penicillin production by $P$. chrysogenum based on research in pure cultures.

The complete genome sequence of $P$. chrysogenum [2] revealed 20 putative polyketide synthase genes (PKS), 10 non-ribosomal peptide synthase (NRPS) genes and 2 genes encoding hybrid NRPS-PKS enzymes [3,4]. Most of these genes are not significantly transcribed under standard laboratory conditions [5-10] and, consequently, their functional and physiological roles remains to be determined.

The contribution of many secondary metabolites to evolutionary fitness of the producing organism remains unknown and subject to debate [11-14]. It is generally assumed that fungal penicillin biosynthesis has primarily evolved as a mechanism to combat competing bacteria. However, there is no evidence that fungal penicillin biosynthesis is triggered by the presence of bacteria. Moreover, there is no a priori reason to assume that synthesis of fungal antibiotics it is single-layer defense mechanism. For example, NRPS or PKS gene clusters may enable the synthesis of compounds that complement and/or augment the action of penicillins.

Several strategies have been successfully applied to activate and characterize cryptic gene clusters in filamentous fungi [15]. These methods include inactivation of biosynthesis genes [16], heterologous expression [17] and simulation of conditions that might activate gene clusters in natural environments $[5,6,18]$. A successful example the latter approach was achieved by co-culturing Aspergillus nidulans with Streptomyces hygroscopicus. Genome wide expression analysis of $A$. nidulans revealed that cocultivation led to specific expression of a polyketide gene cluster that was silent under standard conditions for laboratory growth of the fungus [18]. This example supports the notion that microbial interactions in natural environments may be a direct trigger for production of secondary metabolites and other means of 'microbial warfare'. Simulation of these interactions by co-cultivation in the laboratory is therefore a rational strategy to identify natural antimicrobial compounds and mechanisms. Indeed, this approach has been successfully used to study interactions between microorganisms [19-22], allowing the identification of a wide range of responses, ranging from increased production of stress-response related compounds [23], induction of biofilm formation and modulation of virulence expression [20]. By providing in-depth knowledge on interaction mechanisms it provides an important tool for understanding the physiology of microorganisms, communication between microbial species and drug discovery [18].

The dynamic nature of microbial interactions in mixed cultures limit the value of static (single time point) gene expression studies. Time-course expression experiments, in which transcriptional responses to an external stimulus are recorded over time [24] have been applied successfully to a wide range of perturbations [25-29].

The original discovery of penicillin by Fleming was unintentionally based on a co-cultivation experiment, involving interaction of a Penicillium strain with bacteria on solid medium plates [30]. Surprisingly however, interaction of this fungus with prokaryotes has subsequently not been studied in detail. The objective of the present study is to investigate the response of $P$. chrysogenum to co-cultivation with $B$. subtilis, a penicillin-sensitive Gram-positive bacterium. To this end, steady-state chemostat cultures of P. chrysogenum Wisconsin 54-1255 were inoculated with B. subtilis. The dynamic transcriptional and physiological responses of $P$. chrysogenum in the resulting mixed cultures were monitored and analyzed. Several differentially expressed genes potentially reflected responses to the bacterium. To test whether any bacterial signaling molecules are responsible for differential expression of selected fungal genes, $P$. chrysogenum cultures were supplemented with supernatant of $B$. subtilis cultures, supernatants from mixed cultures and with heat-inactivated B. subtilis. The specific transcriptional responses, identified using microarray, were verified by analysis of fermentation broth and by functional characterization of selected $P$. chrysogenum genes in S. cerevisiae.

\section{Results}

\section{Co-cultivation of $P$. chrysogenum and $B$. subtilis and physiology}

The interaction between $P$. chrysogenum and B. subtilis was studied in controlled chemostat experiments. P. chrysogenum strain Wisconsin 54-1255, an early strain of the penicillin strain improvement lineage [2,31], was grown in an aerobic, glucose-limited chemostat culture at a dilution rate of $0.03 \mathrm{~h}^{-1}$. This dilution rate is much lower than the maximum specific growth rates of $P$. chrysogenum and $B$. subtilis ( $\mu_{\max }=0.14 \mathrm{~h}^{-1}$ and $0.47 \mathrm{~h}^{-1}$, respectively) in batch cultures on the synthetic medium used for the chemostat experiments. Phenylacetate (PAA), which is needed for the efficient production of penicillin-G production by $P$. chrysogenum, was not included in growth media, to enable a focus on other, as yet unknown, antibacterial mechanisms in this fungus. When the P. chrysogenum chemostat cultures had reached stationary phase, they were inoculated with $B$. subtilis. Although both organisms remained 
present during the entire $72 \mathrm{~h}$ of the co-cultivation experiment, the relative bacterial and fungal populations changed over time. During the mixed culture, B. subtilis grew faster than $P$. chrysogenum and, as a consequence, the $B$. subtilis biomass concentration increased by more than three fold while the P. chrysogenum biomass concentration was reduced by half over a $72 \mathrm{~h}$ period (Figure 1 ). Comparison of $P$. chrysogenum biomass dynamics with a theoretical washout $(\mu=0)$ at a dilution rate of $0.03 \mathrm{~h}^{-1}$ confirmed that the fungal biomass was still growing, but slower than the dilution rate, leading to a declining population size in the reactor (Figure 1).

After the bacterial pulse, the characteristics of the fermentation changed. The chemostat was not in steady state anymore and the total biomass increased from $4.037 \pm$ $0.11 \mathrm{~g} \mathrm{l}^{-1}$ to $4.977 \pm 0.29 \mathrm{~g} \mathrm{l}^{-1}$ after $72 \mathrm{~h}$ of mixed culture. The specific oxygen uptake rate and the specific carbon dioxide production rate were decreased from $0.930 \pm 0.021$ to $0.746 \pm 0.047 \mathrm{mmol} \mathrm{g}^{-1} \mathrm{~h}^{-1}$ and from $0.847 \pm 0.038$ to $0.718 \pm 0.052 \mathrm{mmol} \mathrm{g}^{-1} \mathrm{~h}^{-1}$ respectively during $72 \mathrm{~h}$ of mixed culture (Table 1).

Microscopic observation revealed no detectable adhesion of bacterial cells to the fungal hyphae and no morphological change in $P$. chrysogenum, but the morphology of $B$. subtilis changed dramatically during co-cultivation, from rod-shaped bacteria to spherical cells (Figure 2). To investigate whether the $B$. subtilis morphology change was caused by the presence of the fungus or the culture conditions, a control glucose-limited chemostat culture experiment under exactly the same conditions (including medium composition and dilution rate) but with a pure culture of $B$. subtilis was performed. As the culture was

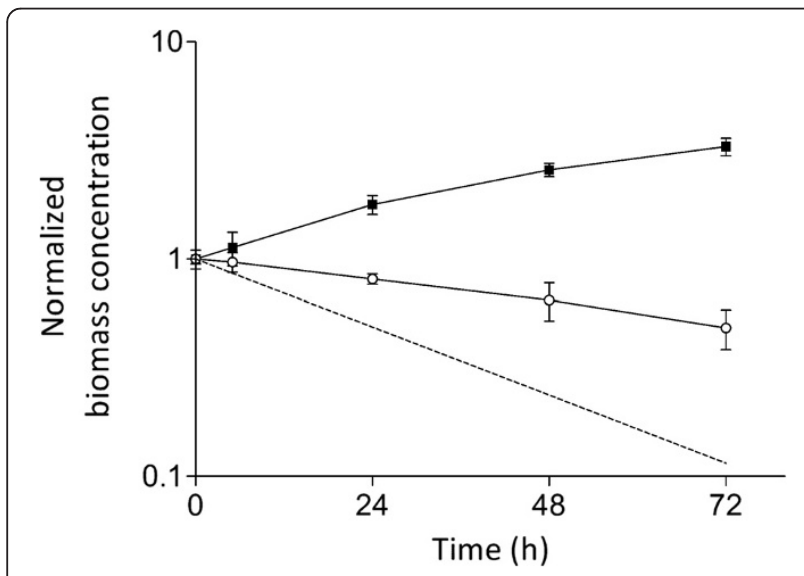

Figure 1 Dynamics of $P$. chrysogenum and $B$. subtilis during co-cultivation. At $\mathrm{t}=0 \mathrm{~h}$, a steady-state, glucose-limited chemostat culture of $P$. chrysogenum, grown in the absence of phenylacetate and at a dilution rate of $0.03 \mathrm{~h}^{-1}$, was inoculated with $B$. subtilis cultures. The data represents the $\mathrm{t}=0 \mathrm{~h}$ normalized biomass concentration of $P$. chrysogenum (o) and $B$. subtilis ( $\bullet$ ). The dashed line represents wash-out at zero specific growth rate. Data points represent average and mean deviation of duplicate experiments. switched from batch to chemostat mode, the typical rod-shaped morphology B. subtilis changed into spherical cells. This indicated that the morphology change during co-cultivation with $P$. chrysogenum was due to the glucose-limited culture conditions rather than to a specific interaction with the fungus.

\section{Global transcriptional responses of $P$. chrysogenum to co-cultivation with $B$. subtilis}

Dynamic experiments are, inherently, richer in information than steady-state cultivation experiments but also more susceptible to experimental variation. Tight control of experimental conditions and of data quality is therefore of paramount importance [32]. In view of their reproducibility, steady-state chemostat cultures are excellent experimental platforms for dynamic perturbation studies $[27,28]$. Hence, to identify fungal genes whose expression would change in reaction to co-cultivation with B. subtilis, steady-state chemostat cultures of $P$. chrysogenum were inoculated with $B$. subtilis and followed over time $(0 \mathrm{~h}$, $5 \mathrm{~h}, 24 \mathrm{~h}, 48 \mathrm{~h}, 72 \mathrm{~h}$ ). The variation among the same time points in independent duplicate chemostat experiments did not exceed 27\%. Analysis with the Significance Analysis of Microarray (SAM) algorithm (http://statweb.stanford.edu/ tibs/SAM/) [33] revealed no fewer than 732 $P$. chrysogenum genes whose expression changed during co-cultivation with $B$. subtilis. K-means clustering of these responsive genes yielded six clusters, with 433 genes displaying an ascending expression profile (clusters 1, 3 and 4) and 299 genes exhibiting a descending profile (cluster 2, $5,6)$ during co-cultivation (Figure 3 and Additional file 1: Table S1). Enrichment analyses using Fischer's Exact statistical test did not reveal any enrichment of MIPS functional categories in clusters with descending profiles (clusters 2, 5 and 6). In contrast, several functional categories were found to be overrepresented in all three clusters comprising ascending profiles (clusters 1, 3 and 4) (Figure 3).

Cluster 1 comprises fast-responding genes, which reached $80 \%$ of their maximum expression level within the first $24 \mathrm{~h}$. This cluster showed overrepresentation of genes in the MIPS categories involved in primary metabolism, protein synthesis, folding and stabilization, energy conservation, electron transport, respiration and mitochondrial activity (Figure 3 ). For example, the gene with the highest fold change after $72 \mathrm{~h}$ of co-cultivation (+50-fold), Pc12g10440, showed strong similarity to the alternative oxidase aox 1 from Aspergillus niger. Cluster 3 contains genes that exhibited slower response profiles and showed an overrepresentation of genes involved in metabolism (Figure 3). In addition to genes with strong similarity to transporters (permeases, maltose transport protein and high-affinity glucose transporter), this category comprised genes with sequence homology to genes encoding 
Table 1 Physiological parameters of co-cultivation of $P$. chrysogenum and $B$. subtilis

\begin{tabular}{|c|c|c|c|}
\hline Time elapsed since inoculation with $B$. subtilis (h) & Total biomass concentration $^{\mathrm{a}}\left(\mathrm{g} \mathrm{l}^{-1}\right)$ & $\mathrm{qO}_{2}{ }^{\mathrm{a}, \mathrm{b}}\left(\mathrm{mmol} \mathrm{g}^{-1} \mathrm{~h}^{-1}\right)$ & $\mathrm{qCO}_{2}{ }^{\mathrm{a}, \mathrm{b}}\left(\mathrm{mmol} \mathrm{g}^{-1} \mathrm{~h}^{-1}\right)$ \\
\hline 0 & $4.04 \pm 0.11$ & $0.93 \pm 0.02$ & $0.85 \pm 0.04$ \\
\hline 24 & $4.32 \pm 0.07$ & $0.90 \pm 0.01$ & $0.81 \pm 0.06$ \\
\hline 48 & $4.69 \pm 0.17$ & $0.78 \pm 0.03$ & $0.75 \pm 0.04$ \\
\hline 72 & $4.98 \pm 0.29$ & $0.75 \pm 0.05$ & $0.71 \pm 0.05$ \\
\hline
\end{tabular}

At $\mathrm{t}=0 \mathrm{~h}$, a steady-state, glucose-limited chemostat culture of $P$. chrysogenum, grown in the absence of phenylacetate and at a dilution rate of $0.03 \mathrm{~h}{ }^{-1}$, was inoculated with $B$. subtilis cultures. Physiological parameters are presented as average and mean deviation of three independent replicate experiments.

a Total biomass is the sum of $P$. chrysogenum and $B$. subtilis biomass. ${ }^{b}$ Specific rates of oxygen consumption and carbon dioxide production (qO $\mathrm{O}_{2}$ and $\mathrm{qCO}_{2}$ ) were calculated from biomass concentrations and manual analysis of the gas composition and gas-flow.

carbohydrate cleaving enzymes such as mutanase, mannosidase and alpha-amylase, to a gene encoding a starvation sensing protein (Pc12g13310) and to a gene showing similarity to polyketide synthase PKS17 from Botryotinia fuckeliana (Pc12g13170). Finally, Cluster 4, which comprises genes exhibiting a continuously increasing profile over the $72 \mathrm{~h}$ co-cultivation period, showed an overrepresentation of genes involved in cellular import (Figure 3). No fewer than five genes with similarity to the Kluyveromyces lactis high-affinity glucose transporter gene HGT1. (Pc18g00150; Pc21g19660; Pc22g09740 and Pc21g19770) and the glucose transporter rco-3 from Neurospora crassa (Pc12g02080) were found in this cluster (Additional file 1: Table S1).

\section{Transcriptional responses of $P$. chrysogenum genes involved in secondary metabolite production to co-cultivation with $B$. subtilis}

P. chrysogenum is primarily known for its ability to synthesize $\beta$-lactam antibiotics. Closer inspection of the non-ribosomal peptide penicillin gene cluster ( $p c b A B$, $p c b C$ and penDE) $[34,35]$ and genes involved in side-chain precursor metabolism did not show differential expression during co-cultivation with $B$. subtilis [36,37]. In addition to the penicillin biosynthesis gene cluster, the $P$. chrysogenum genome sequence [2] harbors 9 other NRPS and 15 NRPS-like, 20 PKS and 3 PKS-like, and 2 hybrid NRPSPKS gene clusters (Figure 4). All these genes potentially encode NRPS and PKS proteins enabling the synthesis of complex secondary metabolites [3,4,38,39] (Figure 4). Cocultivation with $B$. subtilis had only small effects on expression of these NRP and PK gene clusters. Only seven individual genes in these clusters were differentially expressed, of which only Pc12g13170 and Pc16g03800, which share sequence similarity with the polyketide synthase PKS17 from B. fuckeliana [40] and with the polyketide synthase PKS1 from Cochliobolus heterostrophus [41], respectively, were upregulated. However, their absolute expression levels remained very low (Figure 4 and Additional file 1: Table S1).

\section{B. subtilis induced mutanase production in $P$. chrysogenum}

Our data indicated that, in the absence of a penicillin sidechain precursor, other non-ribosomal peptides or polyketides did not replace penicillin as an antibiotic against $B$. subtilis in mixed cultures. Among the top 10 of overexpressed $P$. chrysogenum genes, we focused our attention on two genes found in cluster 3. These two genes, Pc12g07500 and Pc12g13330, shared strong sequence similarity to the alpha-1,3-glucanase mutA from Talaromyces. purpurogerus [42] and were upregulated by 15 fold and 8 fold, respectively after $72 \mathrm{~h}$ of co-cultivation with B. subtilis. Occurrence of alpha-1, 3-glucanase (mutanase) in response to the presence of $B$. subtilis represented a

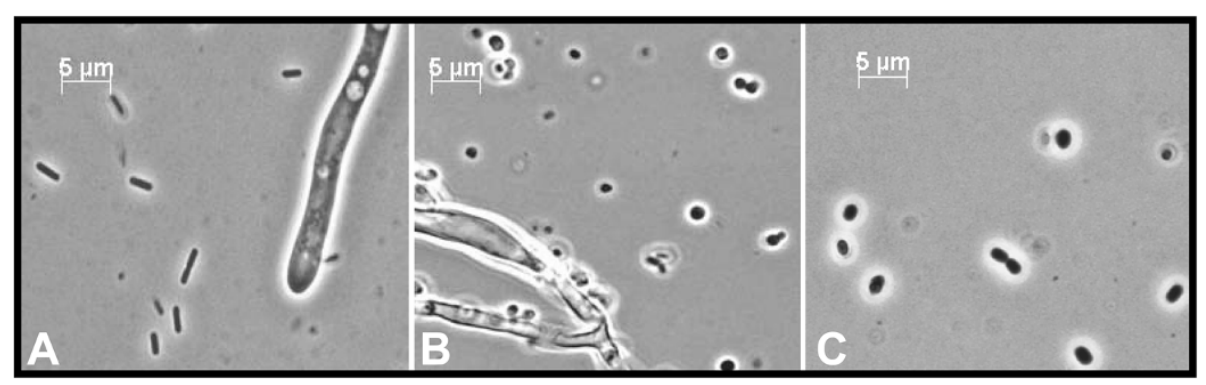

Figure 2 Change of $B$. subtilis morphology in chemostat cultures. A: Mixed culture of $B$. subtilis and $P$. chrysogenum at 0 h; $B$. subtilis cells were pregrown in shake-flask culture and addition to a P. chrysogenum glucose-limited chemostat culture. $\mathbf{B}$ : Mixed culture of $B$. subtilis and P. chrysogenum at 72 h. C: pure culture of B. subtilis after 72 h of glucose-limited cultivation. Pictures taken under oil immersion and $1000 \mathrm{X}$ magnification using a Zeiss Axio imager D1 and an Axio Camera. 


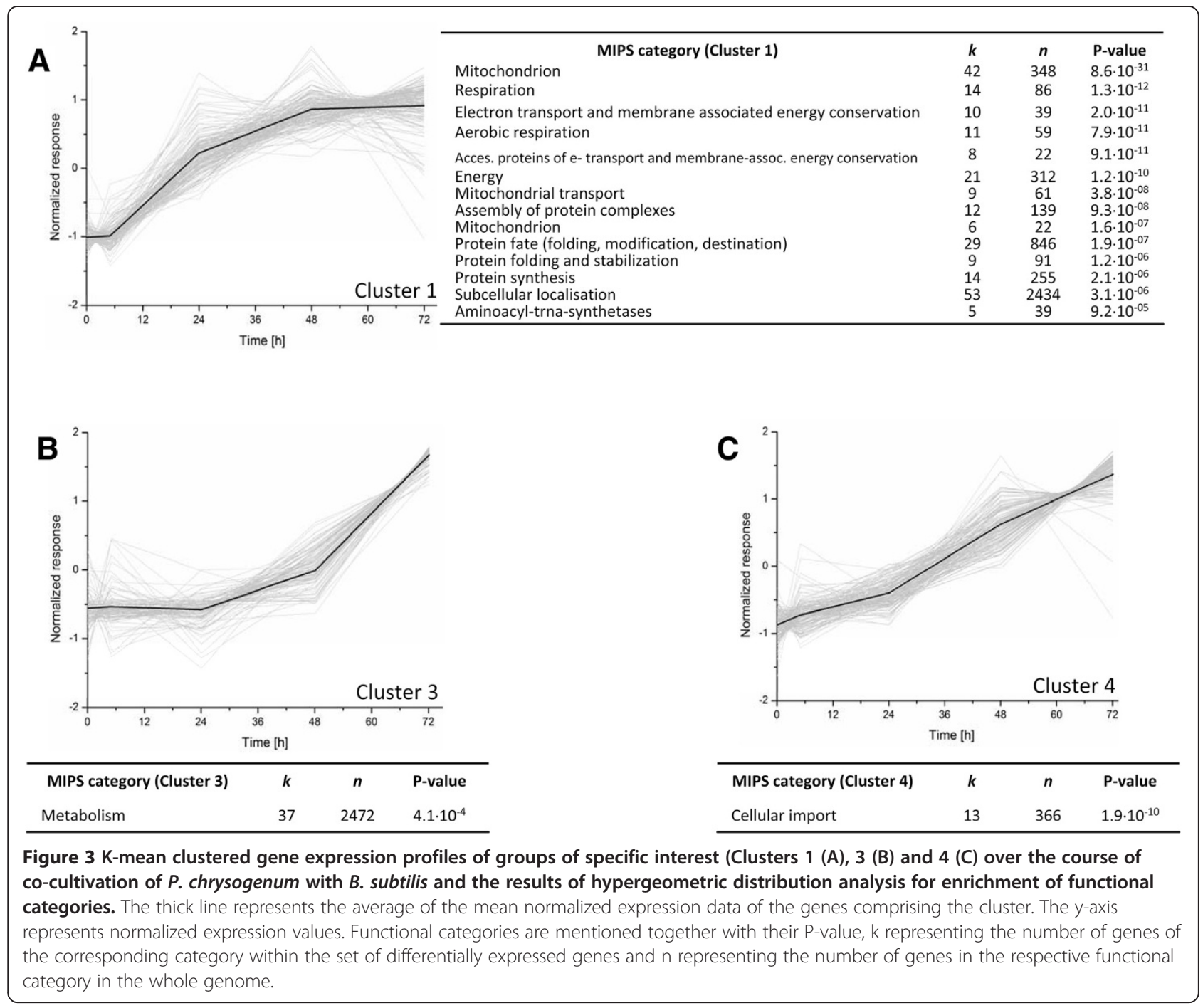

specific response of $P$. chrysogenum, as mutanase activity was not observed in pure cultures of either $P$. chrysogenum or B. subtilis. The presence of mutanase activity in culture supernatants was first observed after $24 \mathrm{~h}$ of mixed cultivation. This activity increased from $0.10 \pm 0.021 \mathrm{U} \mathrm{ml}^{-1}$ at $24 \mathrm{~h}$ to $0.28 \pm 0.034 \mathrm{U} \mathrm{ml}$ ${ }^{-1}$ at $72 \mathrm{~h}$ of co-cultivation even though, during this period, the $P$. chrysogenum biomass concentration decreased from $2.40 \pm 0.037 \mathrm{~g} \mathrm{l}^{-1}$ at $24 \mathrm{~h}$ to $1.43 \pm$ $0.080 \mathrm{~g} \mathrm{l}^{-1}$ at $72 \mathrm{~h}$ (Figure 5).

The upregulation of mutanase genes in P. chrysogenum could theoretically be induced by compounds released by B. subtilis. To test whether extracellular bacterial signaling molecules were sufficient to triggering fungal mutanase synthesis, 24 h-old $P$. chrysogenum shake-flask cultures cultures were aseptically supplied with either $30 \mathrm{ml}$ of filter-sterilized supernatant of a pure B. subtilis culture, $30 \mathrm{ml}$ of filter-sterilized supernatant a from mixed chemostat culture or with heat-inactivated B. subtilis cells. These cultures were allowed to grow for another $72 \mathrm{~h}$ and samples were taken after $0 \mathrm{~h}, 24 \mathrm{~h}, 48 \mathrm{~h}$ and $72 \mathrm{~h}$ for determination of mutanase activity (Figure 6). Mutanase production was not observed when $P$. chrysogenum was co-cultured with $B$. subtilis supernatant or heat inactivated B. subtilis cells. However, the P. chrysogenum cultures did produce mutanase when inoculated with filter sterilized supernatants from 24-h mixed cultures of $P$. chrysogenum and $B$. subtilis. Mutanase activity was also observed in control shake flask mixed culture of $P$. chrysogenum and $B$. subtilis (Figure 6). In any case the growth of $P$. chrysogenum was not inhibited by the B.subtilis culture fractions. In addition, mutan ( $\alpha$ 1,3 glucan) was sufficient to induce mutanase production in $P$. chrysogenum supernatant. In contrast addition to the culture medium of pullulan ( $\alpha 1,4-\alpha 1,6$ glucan), dextran ( $\alpha 1,6$ glucan) and $\beta 1,3$ glucan did not lead to mutanase induction (Figure 6). 


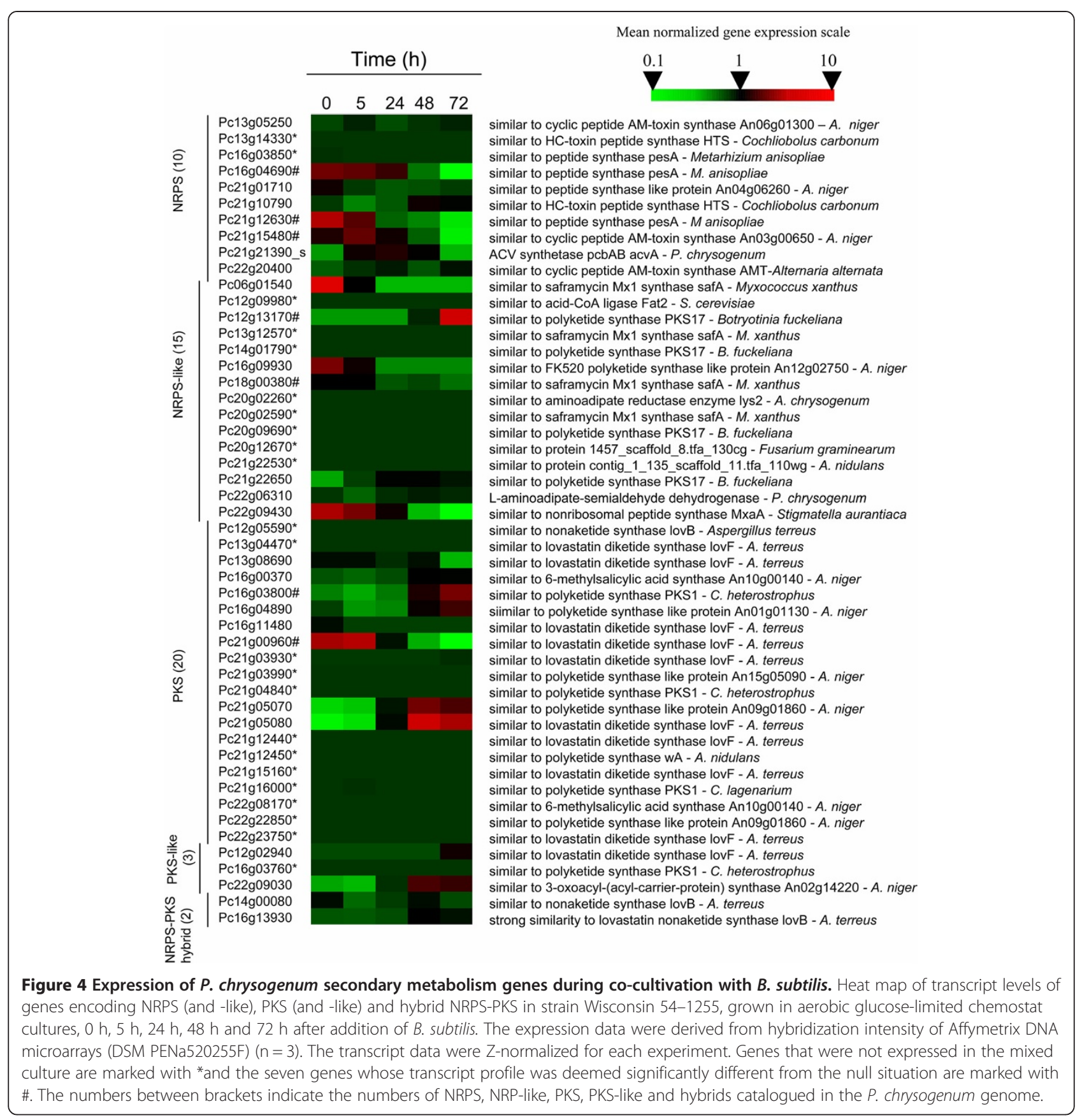

\section{Cloning and functional characterization of two putative $P$. chrysogenum mutanase genes}

To functionally characterize the two upregulated $P$. chrysogenum putative mutanase genes, the coding regions of Pc12g07500 and Pc12g13330 were expressed in S. cerevisiae, a eukaryotic microorganism that does not itself express mutanase. The predicted coding sequence of the putative mutanase Pc12g07500 included a 63-bp 5' sequence predicted to encode an $\mathrm{N}$-terminal signal peptide. Therefore, Pc12g07500 cDNA including the signal peptide was PCR amplified from mRNA isolated from $P$. chrysogenum mycelium, pooled from different 72-h cocultures with $B$. subtilis. The cDNA was inserted in plasmid pAG426GPD-ccdB [43], which placed it under control of the constitutive $T D H 3$ promoter and $C Y C 1$ terminator (pUDE230). When grown in shake-flask cultures on a synthetic medium containing $20 \mathrm{~g} \mathrm{l}^{-1}$ glucose, S. cerevisiae strain IME208, carrying this plasmid, showed a specific growth rate of $0.29 \pm 0.02 \mathrm{~h}^{-1}$. The sequence of the gene in the entry clone was confirmed by 

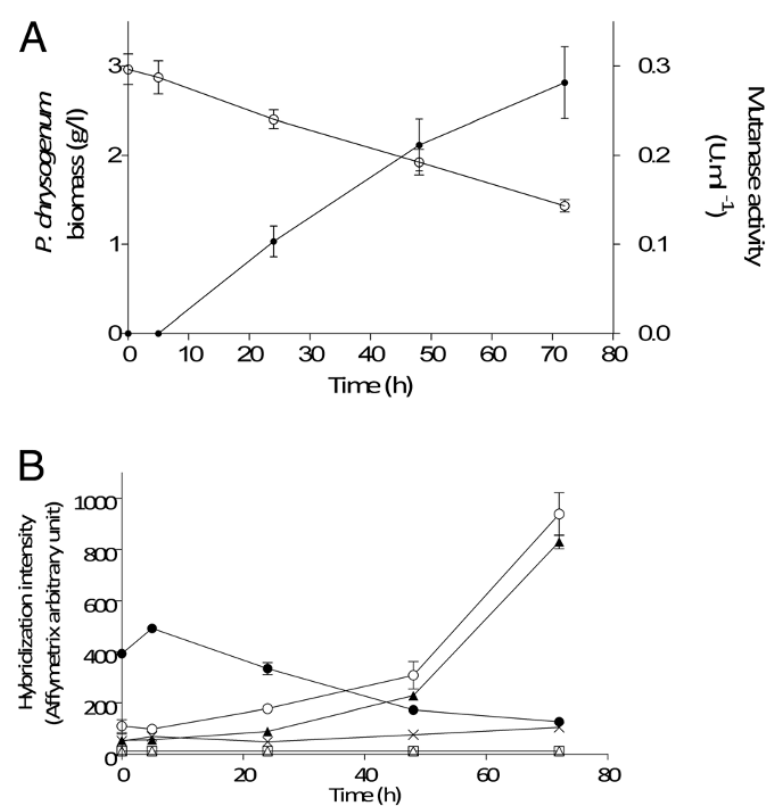

Figure 5 Mutanase production by $P$. chrysogenum during co-cultivation with $B$. subtilis. A- fungal biomass ( $(0)$ and mutanase activity $(\bullet)$ after 0 h, 5 h, 24 h, 48 h and $72 \mathrm{~h}$ of co-cultivation with B. subtilis in aerobic, glucose-limited chemostat cultures. B- Expression of the six putative

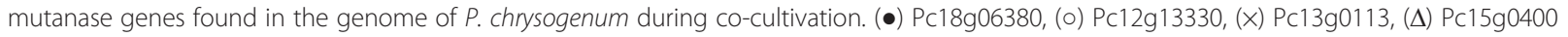

( $\mathbf{\Delta})$ Pc12g07500, (口) Pc13g12810. Data are presented as mean and standard deviation of three independent replicates.

restriction analysis and DNA sequencing. Presence of the expression plasmid was confirmed by diagnostic $\mathrm{PCR}$, and transcription of Pc12g07500 in S. cerevisiae IME208 confirmed by RT-qPCR (Table 2). However, mutanase production was neither observed in cultures of this strain nor in cultures of a negative control strain (S. cerevisiae CEN.PK113-5D containing the control plasmid p426GPD [44]).

The absence of mutanase activity in culture supernatants of S. cerevisiae IME208 might originate from a lack of recognition of the Penicillium signal peptide by the yeast secretion machinery. To circumvent this potential problem, the first 63 nucleotides of Pc12g07500 were replaced by the signal peptide of the S.cerevisiae alpha mating factor [45]. The S. cerevisiae strain IME209, expressing the $\alpha$-factor pre-pro-peptide - P12g07500 chimera, showed a strongly impaired specific growth rate $\left(0.09 \pm 0.01 \mathrm{~h}^{-1}\right)$ on glucose synthetic medium. A mutanase activity of $0.03 \mathrm{U} \cdot \mathrm{ml}^{-1}$ was detected in culture supernatants, confirming that Pc12g07500 encodes an active mutanase.

The amino acid sequence analysis of the second putative mutanase gene, Pc12g1330, did not reveal the presence of a signal peptide. Therefore, its cDNA was directly cloned behind the $\alpha$-factor pre-pro-peptide sequence to promote secretion of the enzyme by S. cerevisiae. In shake flask cultures of the resulting S. cerevisiae strain IME210 on glucose, it showed a specific growth rate of $0.27 \pm 0.01 \mathrm{~h}^{-1}$.
No mutanase activity was detected in IME210 culture supernatant, despite confirmation by RT-PCR that the gene fusion was transcribed (Table 2).

\section{Discussion}

General responses of $P$. chrysogenum to co-cultivation with $B$. subtilis

While co-cultivation experiments under laboratory conditions cannot fully capture the entire complexity of microbial interactions in natural environment, they do enable identification of specific mechanisms by which micro-organisms interact $[18,20-22]$. The present study focused on responses of $P$. chrysogenum to cocultivation with the B. subtilis. A substantial part of the transcriptional response of $P$. chrysogenum to cocultivation could be attributed to competition for glucose, the growth-limiting nutrient used for the chemostat studies. However this has not been experimentally tested since our fermenters were not equipped with rapid sampling port and the actual supernatant sampling procedure was far too long to trust the measured values. When $B$. subtilis was inoculated in a glucose-limited chemostat of $P$. chrysogenum, the bacterium was able to grow faster than the fungus and, over a $72 \mathrm{~h}$ period, was well on the way to outcompete it highlighting a better affinity $\left(\mu_{\max } / \mathrm{Ks}\right)$ of the bacterium for the limited nutrient. The strong up-regulation of $P$. chrysogenum genes including sugar transporters 


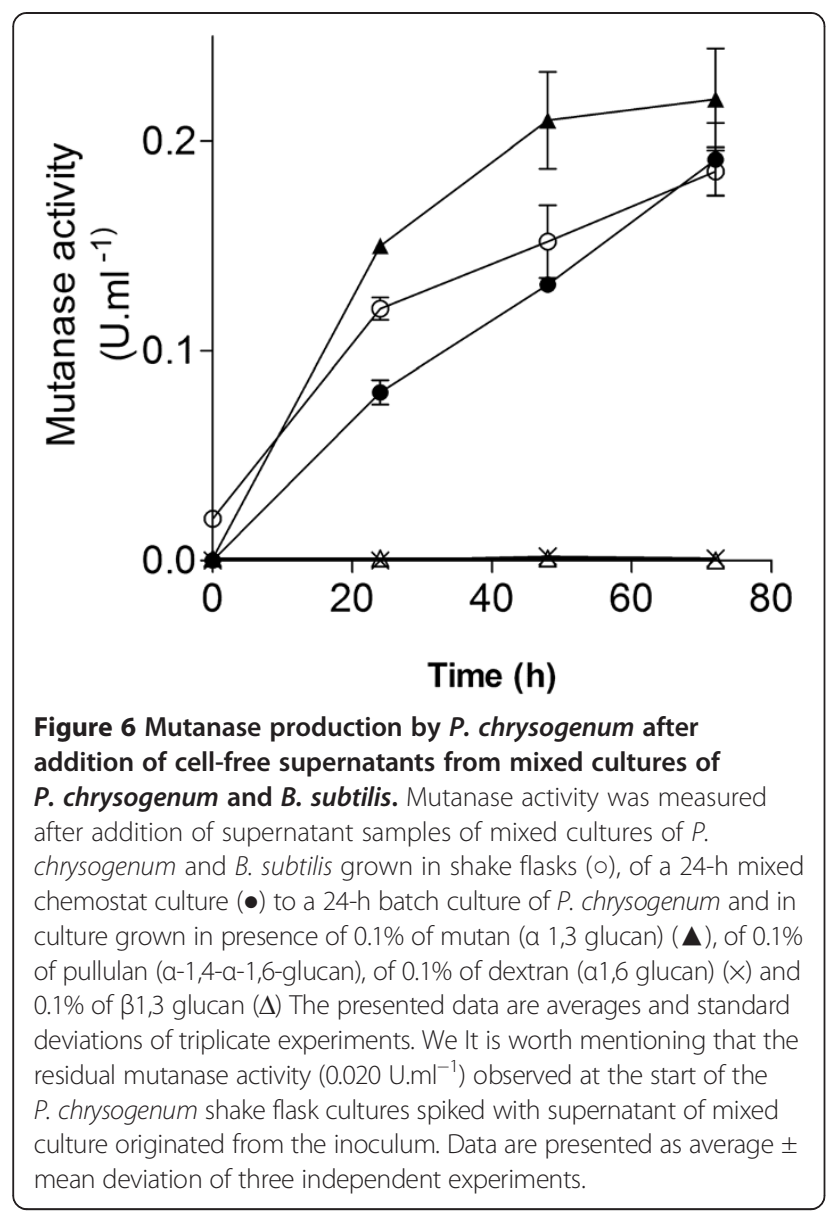

(Figure 3, Cluster 4), including genes encoding putative high-affinity transporters, represents a typical response of a micro-organism that is confronted with competition for glucose as the growth-limiting nutrient [46].

The gene Pc12g10440, which showed the strongest upregulation during co-cultivation with $B$. subtilis, shares strong similarity with the alternative oxidase gene aox 1 from $A$. niger. Alternative oxidases in fungi and plants represent bypass energy coupling sites in the mitochondrial respiratory chain. Their expression is upregulated under a variety of stress conditions, including changes in the supply of, or demand for, carbon, reducing power, and ATP [47]. Interestingly, alternative oxidases have also been directly implicated in the defense against microbes and, in the case of pathogens, with host cells. For example, expression of alternative oxidase in Nicotania attenuata has been shown to contribute to resistance against pathogenic Pseudomonas syringae [48] and, in pathogenic fungi, the enzyme counteracts the host's immune system [49-51].

The side-chain precursor phenylacetic acid, whose addition is essential for high-level production of penicillin $G$ by $P$. chrysogenum, was not included in the growth media used for the present study. $P$. chrysogenum is able to synthesize phenylacetic acid by itself, using Lphenylalanine as a precursor [10]. However, co-cultivation did not affect expression of genes involved in phenylalanine production or catabolism. This result indicated that, at least in this strain background, co-cultivation of a penicillin-sensitive Gram positive bacterium, did not trigger penicillin production. Although the Wisconsin strain of $P$. chrysogenum represents an early strain in the penicillin strain improvement lineage [31], we cannot exclude the possibility that its penicillin biosynthetic pathways had already been deregulated as a result of strain improvement, thereby masking induction by the presence of bacterial cells. However, unexpectedly and in contrast to a previous study on co-cultivation of Aspergillus nidulans with Streptomyces hygroscopicus [18], P. chrysogenum did not induce other secondary metabolite biosynthetic gene clusters upon in response to the presence of B. subtilis (Figure 4).

\section{Expression of fungal mutanase activity results from cross} talk between $P$. chrysogenum and $B$. subtilis

Although we were unable to connect co-cultivation of $P$. chrysogenum with a prokaryote to production of lowmolecular weight fungal metabolites, co-cultivation clearly triggered the expression of two genes encoding putative $\alpha$ 1, 3 glucanases (Pc12g07500 and Pc12g13330). Synthesis of mutanase ( $\alpha$-1,3-glucanase, EC 3.2.1.59) is induced in several fungi and bacteria when mutan ( $\alpha-1,3$-glucan) or oligosaccharides such as raffinose are present in the growth medium [52-54]. Mutanase production by Trichoderma harzianum is triggered by sugars or molecule with $\alpha-1,3$ linkages, consistent with the ability of the enzyme to act on $\alpha-1,3$ linkages in bacterial biofilms and extracellular polysaccharides such as $\alpha$-mutan [55].

Upregulation of the putative mutanase genes Pc12g07500 and Pc12g13330 required the presence of the two

Table 2 Transcript levels of heterologously expressed putative mutanase genes from $P$. chrysogenum in S. cerevisiae

\begin{tabular}{|c|c|}
\hline Gene and S. cerevisiae strain/relevant genotype & Gene expression relative to reference gene $A C T 1$ \\
\hline 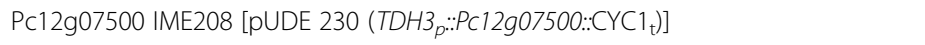 & $1.52 \pm 0.16$ \\
\hline Pc12g07500 IME209 [pUDE 249 (TDH3 $::$ MF(Alpha) $1^{1-270}-$ Pc12g07500- $\left.\left.\Delta^{1-63}: . \mathrm{CYCl}_{t}\right)\right]$ & $1.49 \pm 0.33$ \\
\hline Pc12g13330 IME210 [pUDE 250 (URA3 TDH3 & $1.13 \pm 0.08$ \\
\hline
\end{tabular}

Expression levels were estimated by RT-qPCR using ACT1. Data are average \pm mean deviation of duplicate analyses. 
microorganisms simultaneously. Supernatant of pure $B$. subtilis culture or heat inactivated $B$. subtilis cells were not sufficient to induce the expression of these genes (Table 2), suggesting that the triggering molecule(s) is (are) produced by $B$. subtilis in response to the presence of $P$. chrysogenum. Induction of the mutanase genes during co-cultivation could, for example, result from the formation of $\alpha-1,3$ glucan containing exopolysaccharide by $B$. subtilis in response to co-cultivation by the fungus. This bacterial response could then be countered by the production of mutanase by the fungus. Several pathogenic bacteria in environment reside in exopolysaccharide biofilm which protects bacterial cells from antibiotics [56]. If enzymes produced against these pathogenic bacterial exopolysaccharides in mixed culture enable bacterial biofilm degradation, this might potentiate fungal antibiotics by facilitating access to the bacteria.

\section{P. chrysogenum Pc12g07500 is an atypical fungal mutanase without a mutan binding domain}

Of the two putative mutanase genes that were upregulated during co-cultivation, only Pc12g07500 yielded extracellular mutanase activity when expressed in Saccharomyces cerevisiae. The genome sequence of $P$. chrysogenum [2] harbors six genes that share similarity to the mutA genes from Trichoderma harzianum and Talaromyces purpurogerus (formely known as Penicillium purpurogenum) (Figure 7). Comparison of the predicted amino acid sequences of these six putative mutanases revealed that only two of them (Pc12g07500 and Pc15g01400) were predicted to contain a signal peptide. Interestingly, the amino acid sequence analysis also revealed that, in contrast to previously characterized fungal mutanases, the Pc12g07500 amino acid sequence was much shorter and missed the C-terminal sequence that corresponds to the $\alpha$-mutan binding domain (Figure 7).

Pc12g13330, which showed a higher sequence similarity to T. purpurogenus MutA, did not harbor an $\mathrm{N}$ terminal sequence corresponding to a signal peptide, but did contain a $\mathrm{C}$-terminal extension corresponding to the mutan binding motif. Of the six P. chrysogenum mutanases, not only Pc12g07500, but also Pc18g06380 missed the $\alpha$-mutan binding domain. However, in contrast to Pc12g07500, Pc18g06380 did not appear to carry a signal peptide and was not expressed during co-cultivation with B. subtilis.

Hitherto, fungal mutanases have been described as strictly extracellular enzymes [42,57]. Interestingly, several of the genes with strong sequence similarity to mutanase genes in the $P$. chrysogenum genome appear to lack excretion signals. 1, 3- $\alpha$-D-glucan has been detected in cell walls of Aspergilllus wentii [58] and Schizosaccharomyces pombe [59], intracellular mutanase-like enzymes may play a role in processing and/or degradation of fungal cell wall components. Expression of the $P$. chrysogenum mutanase gene Pc12g07500 in S. cerevisiae (strain IME209) had a strong negative effect on yeast growth. This is an intriguing observation, since $1,3-\alpha-\mathrm{D}$-glucan has not been reported to occur in $S$. cerevisiae cell walls. Detailed analysis of the mode of growth inhibition of mutanase-expressing strains may yield new insights in yeast cell wall composition and biosynthesis.

\section{Conclusion}

The present study demonstrates that co-cultivation experiments with defined mixed cultures provide a useful tool for identifying microbial interactions. Under the experimental conditions, B. subtilis successfully competed with P. chrysogenum for the glucose, the growth-limiting nutrient. The fungus did not respond to this competition by induction of pathways for antimicrobial secondary metabolites. However, a co-cultivation-dependent expression of an extracellular fungal mutanase was observed, which was triggered by (an) extracellular compound(s) produced by the mixed cultures but not by pure cultures of the two organisms. Heterologous expression in $S$. cerevisiae revealed that of the $P$. chrysogenum genes induced during co-cultivation with $B$. subtilis encoded an extracellular mutanase that differed from previously described fungal mutanases due to the absence of an $\alpha$-mutan binding domain.

\section{Methods}

\section{Strains}

P. chrysogenum Wisconsin 54-1255 (ATCC 28089) was obtained from DSM-Anti-Infectives (Delft, The Netherlands) as spores on rice grains. B. subtilis NCCB 70064, obtained from The Netherlands Culture Collection of Bacteria (NCCB) (http://www.cbs.knaw.nl/collections), was grown at $30^{\circ} \mathrm{C}$ in shake flasks containing $100 \mathrm{ml}$ of synthetic medium (see below). 30\% (v/v) glycerol was added to a 24$\mathrm{h}$ old culture and $1 \mathrm{ml}$ aliquots were stored at $-80^{\circ} \mathrm{C}$. S. cerevisiae strains used and constructed in this study (Table 3) are members of the CEN.PK strain family [60,61]. Stock cultures of all $S$. cerevisiae strains were grown in shake flasks containing $100 \mathrm{ml}$ of synthetic medium (see below) with $20 \mathrm{~g} \mathrm{l}^{-1}$ of glucose as the carbon source. When midexponential phase was reached, sterile glycerol was added to make $30 \%$ glycerol (v/v) and $1 \mathrm{ml}$ aliquots were stored at $-80^{\circ} \mathrm{C}$.

\section{Medium composition and preparations}

Synthetic medium for growth of $P$. chrysogenum was prepared as described [62] and contained, per liter of demineralized water, $8.25 \mathrm{~g}$ glucose monohydrate, $0.8 \mathrm{~g}$

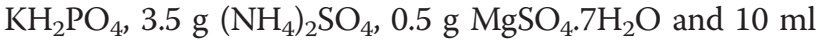
trace elements solution. The $\mathrm{pH}$ was set to 5.5 by addition of $2 \mathrm{M} \mathrm{KOH}$. The trace element solution contained $15 \mathrm{~g} \mathrm{l}^{-1} \mathrm{Na}_{2}$ EDTA. $2 \mathrm{H}_{2} \mathrm{O}, 0.5 \mathrm{~g} \mathrm{l}^{-1} \mathrm{Cu}_{2} \mathrm{SO}_{4} .5 \mathrm{H}_{2} \mathrm{O}$, 


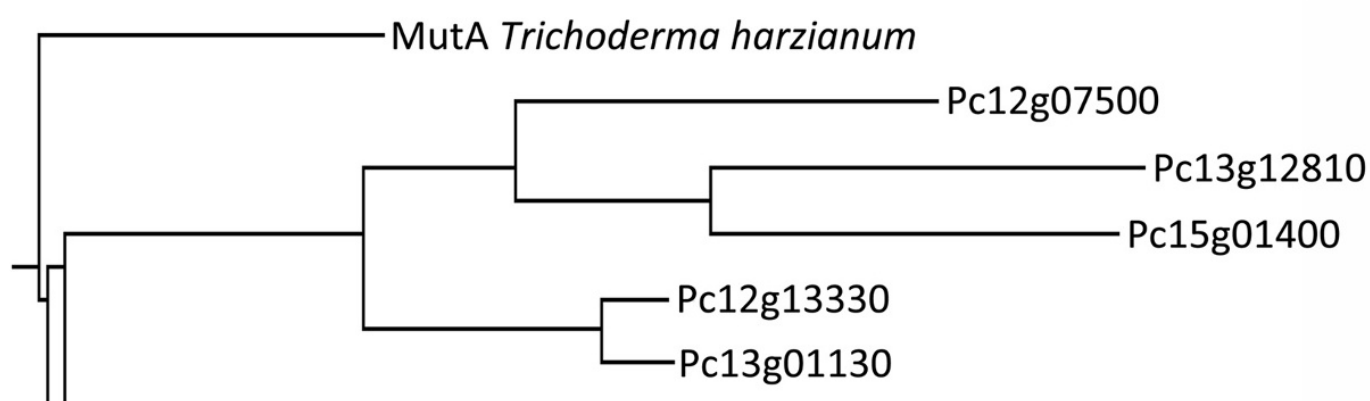

MutA Talaromyces purpurogenus

Pc18g06380

MutA T.harzianum

Pc12g07500
Pc13g12810

Pc13g12810

Pc12g13330

PC13g01130

MutA T.Purp
Pc18g06380

MutA T.harzianum

Pc12g07500

Pc13g12810

PC15g01400

Pc12g1333

Pc13g01130

MutA T.purpurog.

MutA T. harzianum

Pc12g07500

PC13g12810

Pc12g013330

Pc13g01130

MutA T.purpurog

Pc18g06380

MutA T.harzianum

Pc12g07500

Pc13g12810

Pc15g01400

PC12g13330

MutA T. purpurog.

Pc18g06380

MutA T.harzianum

Pc12g07500

Pc13g12810

PC15g01400

Pc12g13330
Pc13g01130

MutA T.purpurog.

Pc18g06380

MutA T.harzianum

Pc12g07500

PC13g12810

Pc15g01400

Pc12g13330

Puta T. purpurog.

Pc18g06380

MutA T.harzianum

Pc12g07500

Pc13g12810

Pc15g01400

PC12g1333

Pc13g01130

MutA T.purpurog.

Pc18g06380

MutA T.harzianum

PC12g07500

Pc13g12810

PC12g13330

Pc13g01130

MutA T. purpurog.

MutA T.purpur

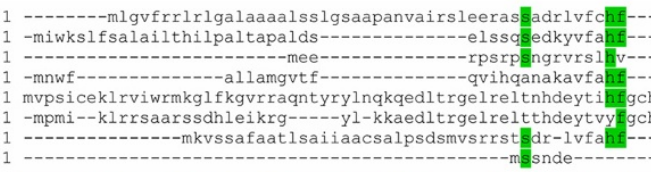

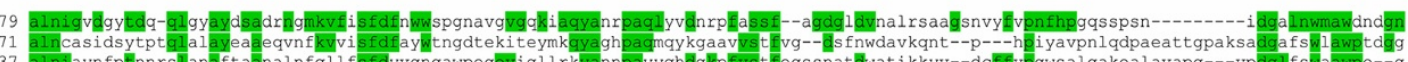

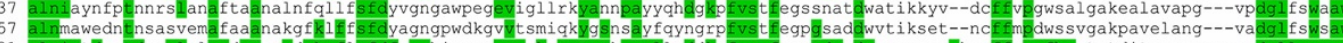
31 alniqt dpytdq-qlq1aydsaanidmkvfl sfdfswhieqagev

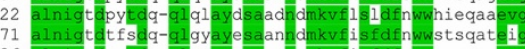
alniqt doptd-t

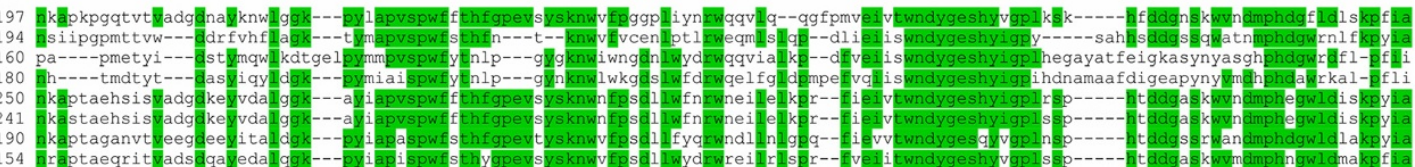

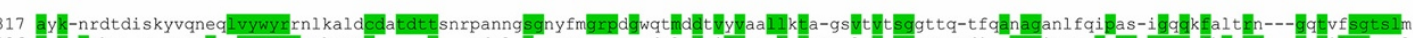

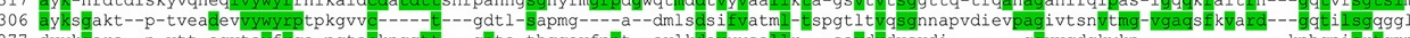
277 dvykgara--n-vtt-egvtawf

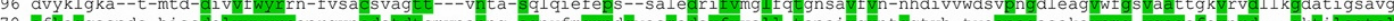

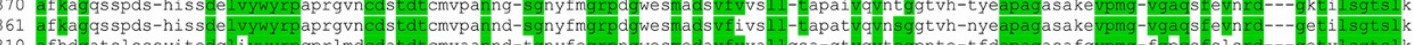

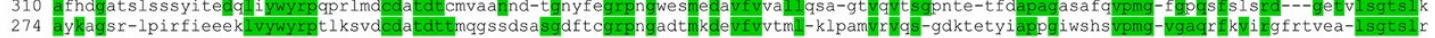

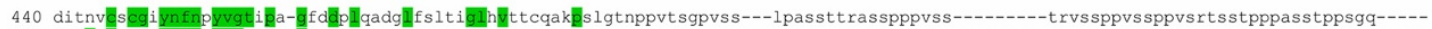

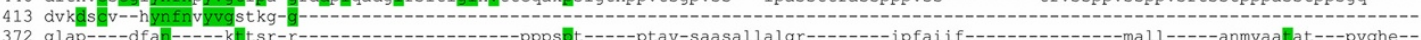
372 glap----dfan-----k 414 eisht Cegdfnnfnawvgsvsg-g----------------imsssd-----ttsi-dladqacvegkgaydfndlcsftcsygycpvgac---tcermgva--

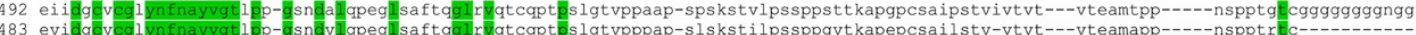
483 evidgovcgl yn nayvgt 1 pp-gsndv qpegl saf tqgl rvqtcqpt slgtvpppap-slskstilpssppgvtkapepcsailstv-vtvt---vteamapp-----nspptr

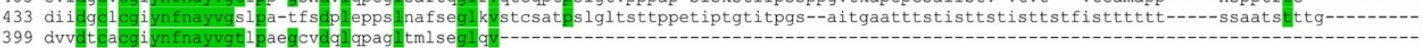

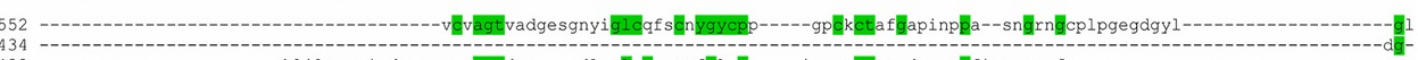
432 - 612 ggngngnvgggggggggggggggg-----------sra i i agt gpd----nysglcs fc 91 ggngngnvggggggggggggggg----42 ------onginal

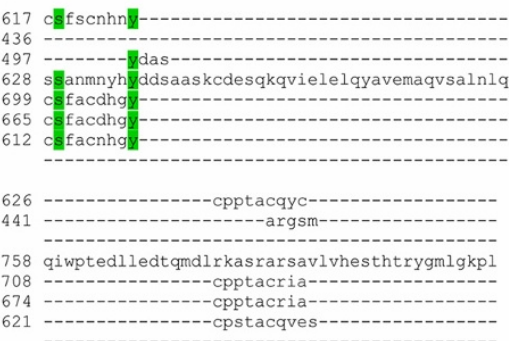

Figure 7 (See legend on next page.) 
(See figure on previous page.)

Figure 7 Comparison of putative mutanase ( $\mathbf{a}-\mathbf{1}, 3$ glucanase) encoding genes in $\mathbf{P}$. chrysogenum. Top panel- Phylogenetic tree based on Clustal-X alignment of predicted amino acid sequences of P. chrysogenum Pc12g07500 (accession number: CAP80377.1), PC12g13330 (CAP80960), Pc13g12810 (CAP92350), Pc13g01130 (CAP91182), Pc15g01400 (CAP83026), Pc18g06380 (CAP94862), Trichoderma harzianum MutA (ADZ45396.1) and Talaromyces purpurogenus MutA (AF214481_1). The tree was constructed using TREECON for Windows. Bottom panel- Amino acid sequence alignment of the previously mentioned proteins. Amino acids highlighted in green represent positions that are conserved in at least $50 \%$ of the aligned sequences.

$2 \mathrm{~g} \mathrm{l}^{-1} \mathrm{MnSO}_{4} \mathrm{H}_{2} \mathrm{O}, 2 \mathrm{~g} \mathrm{l}^{-1} \mathrm{ZnSO}_{4} .7 \mathrm{H}_{2} \mathrm{O}, 4 \mathrm{~g} \mathrm{l}^{-1}$ $\mathrm{FeSO}_{4} \cdot 7 \mathrm{H}_{2} \mathrm{O}$ and $0.5 \mathrm{~g} \mathrm{l}^{-1} \mathrm{CaCl}_{2} \cdot 2 \mathrm{H}_{2} \mathrm{O}$. The $\mathrm{pH}$ of the trace element solution was set at 6.0 by the addition of $\mathrm{NaOH}$. Concentrated medium without glucose was heat autoclaved at $121^{\circ} \mathrm{C}$. After media sterilization, a concentrated glucose solution, separately autoclaved at $110^{\circ} \mathrm{C}$, was added. For cultivation of $B$. subtilis, the same medium was used, but with the addition of $50 \mathrm{mM}$ MES and with an initial $\mathrm{pH}$ of 6.5 . Synthetic medium for growth of $S$. cerevisiae contained, per liter of demineralized water, $5 \mathrm{~g}\left(\mathrm{NH}_{4}\right)_{2} \mathrm{SO}_{4}, 3 \mathrm{~g} \mathrm{KH}_{2} \mathrm{PO}_{4}, 0.5 \mathrm{~g} \mathrm{MgSO} 4 \cdot 7 \cdot \mathrm{H}_{2} \mathrm{O}$ and trace elements [5]. Vitamins [5] were added after heat sterilization of the medium at $120^{\circ} \mathrm{C}$ for $20 \mathrm{~min}$. Glucose was separately sterilized at $110^{\circ} \mathrm{C}$ and added to a final concentration of $20 \mathrm{~g} \mathrm{~L}^{-1}$.

\section{Pure and mixed-culture growth experiments}

P. chrysogenum Wisconsin 54-1255 was grown in steadystate, aerobic and glucose-limited chemostat cultures. Chemostat cultures were grown at $25^{\circ} \mathrm{C}$ in 21 turbinestirred bioreactors (Applikon, Schiedam, The Netherlands) with a working volume of $1.8 \mathrm{~L}$, as described previously $[5,6,62]$. In the batch phase a working volume of $1.5 \mathrm{~L}$ was maintained. The $\mathrm{pH}$ was adjusted to 6.5 and then kept constant at 6.5 through the automatic addition of $2 \mathrm{M} \mathrm{NaOH}$. The bioreactor was sparged with air at a flow rate of $900 \mathrm{ml} / \mathrm{min}$ using a Brooks mass-flow controller (Brooks Instruments, Hatfield, PA). Spores immobilized on rice grains were welled in $100 \mathrm{ml}$ sterilized water until the water became dark green. The liquid then was transferred to a new flask and served as inoculum. To protect the germination process the stirrer speed was initially set at $350 \mathrm{rpm}$. The dissolved-oxygen concentration was continuously monitored with an oxygen electrode (AppliSens, Schiedam, The Netherlands). When dissolved oxygen reached $60 \%$ of air saturation, the stirrer speed was increased to $500 \mathrm{rpm}$ and, subsequently, to $750 \mathrm{rpm}$ to keep dissolved oxygen concentration above $50 \%$ of air saturation. To prevent excessive foaming, antifoam Silcolapse 5020 (Bluestar Silicones, East Brunswick NJ) was discontinuously added at timed intervals $(6 \mathrm{~s}$ on, every $7 \mathrm{~min}$, $\left.1.0 \mathrm{ml} \mathrm{h}^{-1}\right)$. The off-gas was cooled using a condenser $\left(4^{\circ} \mathrm{C}\right)$ and dried with a Perma Pure dryer (MD-110- 48P-4, Permapure, Toms River, NJ). Concentrations of $\mathrm{CO}_{2}$ and $\mathrm{O}_{2}$ in the off-gas were measured with a NGA 2000 Rosemount analyzer (Rosemount Analytical, Solon, OH). Offgas flow rate was measured with a SAGA digital flow meter (Ion Science, Cambridge, United Kingdom). The continuous-feed phase was initiated when the $\mathrm{CO}_{2}$ concentration in the off gas reached $0.3 \%$. A dilution rate of $0.03 \mathrm{~h}^{-1}$ was set by continuous addition of fresh medium with a calibrated peristaltic pump (Masterflex, Vernon Hills, IL). To keep the culture volume constant, culture broth was automatically removed at regular time intervals by applying an overpressure to the reactor by a system of valves [63].

Precultures of $B$. subtillis were grown by inoculating $1 \mathrm{ml}$ of $B$. subtilis glycerol stock into $100 \mathrm{ml}$ of glucose synthetic medium. After incubation in an orbital shaker at $30^{\circ} \mathrm{C}$ and at $200 \mathrm{rpm}$ for $24 \mathrm{~h}$, a volume of $10 \mathrm{ml}$ was inoculated into $200 \mathrm{ml}$ of glucose synthetic medium in a 1-l shake flask and incubated at $30^{\circ} \mathrm{C}(200 \mathrm{rpm})$. After $24 \mathrm{~h}$ of incubation, when the culture had reached exponential phase, cells were separated aseptically by centrifuging for $20 \mathrm{~min}$ at $4^{\circ} \mathrm{C}$ and at $13000 \times g$, washed twice and re-suspended in $50 \mathrm{ml}$ sterile $P$. chrysogenum synthetic medium. The resulting cell suspension, containing ca. $1.8 \mathrm{~g}$ dry weight $B$. subtilis biomass was then aseptically added to to a steady-state chemostat culture of $P$. chrysogenum bioreactor. The resulting mixed culture

Table 3 S. cerevisiae strains used and constructed in this study

\begin{tabular}{|c|c|c|}
\hline Strain & Genotype & Reference \\
\hline CEN.PK 113-5D & MATa SUC2 MAL2-8C URa3-52 & Euroscarf \\
\hline CEN.PK 113-7D & MATa SUC2 MAL2-8C & Euroscarf \\
\hline IME 208 & MATa SUC2 MAL2-8C ura3-52 pUDE 230 (URA3 TDH3p::PC12g07500::CYC1 $)$ & This work \\
\hline IME 209 & MATa SUC2 MAL2-8C ura3-52 pUDE 249 (URA3 TDH3 & This work \\
\hline IME 210 & MATa SUC2 MAL2-8C ura3-52 pUDE 250 (URA3 TDH3 & This work \\
\hline IME 211 & MATa SUC2 MAL2-8C ura3-52 p426GPD (URA3 TDH3 $\left.{ }_{p}:-:-: \mathrm{CYC1}_{t}\right)$ & This work \\
\hline
\end{tabular}


was then followed for $72 \mathrm{~h}$ while samples were taken for analysis of biomass and metabolites, microscopic observations and transcriptome analysis (samples times $5 \mathrm{~h}$, $24 \mathrm{~h}, 48 \mathrm{~h}$ and $72 \mathrm{~h}$ after addition of $\mathrm{B}$. subtilis).

Effects of B. subtilis culture supernatant, supernatant from mixed cultures, and heat-inactivated B. subtilis cells and addition of $0.1 \%$ mutan (kindly provided by Prof. Malgorzata Pleszczynska, Maria Curie-Sklodowska University, Lublin, Poland), $0.1 \%$ pullulan (Megazyme International Wicklow, Ireland) and $0.1 \%$ dextran (Megazyme) on $P$. chrysogenum were checked in shake-flask experiments. $P$. chrysogenum was grown in $100 \mathrm{ml}$ glucose synthetic medium in $500 \mathrm{ml}$ flask at $25^{\circ} \mathrm{C}$, shaken at $200 \mathrm{rpm}$. Fermentation broth of exponentially growing $B$. subtilis cultures and culture samples taken from $24 \mathrm{~h}$ mixed chemostat cultures were filtered through $0.20 \mu \mathrm{m}$ filters (Supor-200, $47 \mathrm{~mm}$, Pall Life Sciences, East Hills, $\mathrm{NY}$ ). $30 \mathrm{ml} \mathrm{B}$. subtilis supernatant and $30 \mathrm{ml}$ of mixedculture supernatant were added aseptically to different 24-h P. chrysogenum cultures. Effects of addition of mutan, pullulan and dextran on mutanase induction in P. chrysogenum were checked in shake-flask experiments. The strain was grown in synthetic medium with $0.1 \%$ of mutan, $0.1 \%$ pullulan or $0.1 \%$ dextran. These cultures were allowed to grow for another $72 \mathrm{~h}$, during which samples were taken at $24 \mathrm{~h}$ intervals for determining mutanase activity. All cultivation experiments were performed in triplicate.

Heat-inactivated B. subtilis cells were generated by autoclaving $30 \mathrm{ml}$ of exponentially growing $B$. subtilis culture for $20 \mathrm{~min}$ at $121^{\circ} \mathrm{C}$. Killed cells were separated aseptically by centrifuging for $20 \mathrm{~min}$ at $4^{\circ} \mathrm{C}$ and at $13000 \times g$, washed twice and re-suspended in $10 \mathrm{ml}$ of with sterile synthetic medium. The resulting suspension was then aseptically added to a 24-h P. chrysogenum shake-flask culture. Control experiments were performed by using exponentially growing B. subtilis cells instead of killed cells.

\section{Analytical methods \\ Determination of culture dry weight}

For P. chrysogenum, $10 \mathrm{ml}$ fermentation broth was filtered over preweighed glass fiber filters Type A/E (Pall Life Sciences). The filters were washed with demineralised water and dried for $20 \mathrm{~min}$ at $600 \mathrm{~W}$ in a microwave oven and were weighed immediately. For B. subtilis, $10 \mathrm{ml}$ fermentation broth was filtered over preweighed $0.45 \mu \mathrm{m}$ filters (Supor-450, $47 \mathrm{~mm}$, Pall Life Sciences). The filters were washed with demineralised water and dried for $20 \mathrm{~min}$ at $350 \mathrm{~W}$ in a microwave oven and were weighed immediately. For mixed cultures, $10 \mathrm{ml}$ of culture sample was filtered over preweighed glass fiber filters. The filters were washed three times with $10 \mathrm{ml}$ of demineralised water so that all the bacterial biomass passed through the glass fiber filters; the combined filtrate was collected. The glass fiber filters were dried for $20 \mathrm{~min}$ at $600 \mathrm{~W}$ in a microwave oven and were weighed immediately. The collected filtrate was passed through preweighed $0.45 \mu \mathrm{m}$ filters. The filters were washed with demineralised water and dried for $20 \mathrm{~min}$ at $350 \mathrm{~W}$ in a microwave oven and were weighed immediately.

\section{Glucose measurement}

Glucose in culture supernatants was analyzed on a Waters 2695 HPLC (Waters, Milford, MA) equipped with an Aminex HPX-87H column (Bio-rad, Hercules, CA) which was coupled to a Waters 2487 dual $\lambda$ absorbance detector (Waters) at $60^{\circ} \mathrm{C}$ with $5 \mathrm{mM} \mathrm{H}_{2} \mathrm{SO}_{4}$ as the mobile phase. Supernatant was separated from the biomass by filtration using a $0.2 \mu \mathrm{m}$ filter.

\section{Microscopy}

Microscopic observations of the mixed culture were made with a Zeiss Axio imager D1 equipped with an Axio Camera (Carl Zeiss, Jena, Germany).

\section{Mutanase assay}

Mutanase activity was assayed by incubating $0.5 \mathrm{ml}$ of culture supernatant and $0.5 \mathrm{ml}$ of a $0.2 \%(\mathrm{w} / \mathrm{v})$ suspension of dextranase-treated mutan in $0.05 \mathrm{M}$ potassium phosphate buffer, pH 6.5 at $45^{\circ} \mathrm{C}$ (kindly provided by Prof. Malgorzata Pleszczynska, Maria Curie-Sklodowska University, Lublin, Poland). After 60-min incubation with shaking, the insoluble mutan was centrifuged (13000 rpm for $5 \mathrm{~min}$ ) and the released reducing sugars were estimated by the Somogyi-Nelson method [64] using D-glucose as a standard. One unit of mutanase activity (U) was defined as the amount of the enzyme that catalyzes the release of reducing sugars equivalent to $1 \mu \mathrm{mol}$ per minute under the experimental conditions [55].

\section{RNA extraction}

To isolate $P$. chrysogenum RNA, mixed-culture samples were filtered through glass fiber filters within seconds, the filter with mycelium was quenched in liquid nitrogen and stored at $-80^{\circ} \mathrm{C}$ until use. Total RNA was extracted by using Trizol reagent and acid-phenol chloroform for RNA extraction and purified by the RNeasy mini kit by Quiagen (Venlo, Netherlands). Quality of the purified RNA was verified by the Agilent 2100 bioanalyzer (Agilent, Santa Clara, CA). To isolate $S$. cerevisiae RNA, cells were collected by rapid filtration and stored at $-80^{\circ} \mathrm{C}$ until use. Total RNA extraction was performed using acid-phenol chloroform for RNA extraction and $3 \mathrm{M} \mathrm{Na}$ acetate as described previously in [65].

\section{Microarray and transcriptome analysis}

Chemostat culture samples $(60 \mathrm{ml})$ were rapidly sampled and filtered over a glass fiber filter (Type A/E, Pall Life 
Sciences, East Hills, NY). The filter containing the mycelium was immediately wrapped in aluminum foil, quenched in liquid nitrogen and stored at $-80^{\circ} \mathrm{C}$. Samples were processed as described [5,6,8,10]. Acquisition and quantification of microarray images and data filtering were performed using Affymetrix GeneChip Operating Software (GCOS version 1.2). Arrays were globally scaled to a target value of 100, using the average signal from all probe sets. Arrays were analyzed as previously described [10]. Significant changes in expression of the replicate arrays experiments were assessed statistically by using the software Significance Analysis of Microarray (SAM version 1.21) [33]. Fold change (FC) was set to 2 and false discovery rate to $2 \%$. Transcriptome data analyzed in this study have been deposited at the Genome Expression Omnibus database http://www.ncbi.nlm.nih.gov/geo/) under the accession number GSE53286. Expression data were K-mean clustered using GeneData Expressionist software version 5.0 (Genedata, Basel, Switzerland). Clusters were analyzed for enrichment of MIPS categories, assessed by Fisher's Exact test employing hypergeometric distribution with a p-value cut-off of $5.10^{-4}$ (with Bonferroni correction) [66].

\section{Cloning and functional characterization of $P$. chrysogenum genes in S. cerevisiae}

Pc12g07500 cDNA was PCR amplified using Phusion Hot-Start Polymerase (Finnzymes, Landsmeer, The Netherlands), using primer pairs AttbPc12g07500-FW/ AttbPc12g07500-RV (Table 4) and P. chrysogenum cDNA prepared from mRNA of pooled mixed-culture samples. The purified PCR product was cloned in $\mathrm{pDONR}^{\mathrm{m}} 221$ (Invitrogen, Carlsbad, CA) by the BP clonase $^{\mathrm{Tm}}$ reaction, resulting in entry clone pUD254. This entry clone was then further cloned, using the LR clonase ${ }^{\mathrm{Tx}}$ reaction, into the destination $S$. cerevisiae expression vector pAG426GPD$c c d b$ [43], which carries a $T D H 3$ promoter and $C Y C 1$ terminator upstream and downstream of the att recombination sites. This resulted in the expression vector pUDE230, which carries Pc12g07500 cDNA under the control of the TDH3 promoter.

To facilitate secretion of the mature protein in S. cerevisiae, the signal peptide region in Pc12g07500 was replaced with $S$. cerevisiae $\alpha$-factor prepropeptide [45]. The gene fragment coding for Pc12g07500 without signal peptide was PCR amplified using primer pair Pc12g07500 SpeIFW/Attb Pc12g07500-RV (Table 4) and P. chrysogenum cDNA pool prepared from mRNA isolated from mixed culture sample. S. cerevisiae $\alpha$-factor prepropeptide cDNA was PCR amplified using primer pair Attb MF(Alpha)1FW/MF(Alpha)1 SpeI-RV (Table 4) and DNA sample isolated from S. cerevisiae CEN.PK113-7D [67]. Both the PCR products were purified and restricted with SpeI, followed by ligation with T4 DNA ligase. The ligation mixture was used as template to perform PCR using primer pair Attb MF(Alpha)1-FW/Attb Pc12g07500-RV and the target DNA fragment was size-selected and gel purified [68]. The purified PCR product was cloned in pDONR ${ }^{\mathrm{m}}$ 221 in a BP clonase ${ }^{\mathrm{Tm}}$ reaction to get entry clone pUD288. The obtained entry clone pUD 288 was further recombined in LR clonase $\mathrm{e}^{\mathrm{Tm}}$ reaction with the destination plasmid pAG426GPD-ccdb [43] to get the expression clone pUDE249.

A synthetic gene containing $S$. cerevisiae $\alpha$-factor prepropeptide and HA tag with Pc12g13330 (2474 bp) was gene optimized using JCat [69] and procured from GenScript (Piscataway, NJ). Restriction sites SpeI (upstream) and

Table 4 Oligonucleotide primers used in this study

\begin{tabular}{|c|c|}
\hline Primer name & Sequence \\
\hline \multicolumn{2}{|l|}{ Cloning } \\
\hline AttbPc12g07500-RV & GGGGACAAGTTTGTACAAAAAAGCAGGCTATGATTTGGAAATCTCTCTITAGTGCTTTGGCC \\
\hline AttbPc12g07500-RV & GGGGACCACTTTGTACAAGAAAGCTGGGTTCACATGCTACCTCTAGCC \\
\hline AttbMF(Alpha)1-FW & GGGGACAAGTTTGTACAAAAAAGCAGGCTATGAGATTTCCTTCAATTTTTACTGC \\
\hline MF(Alpha)1 Spe1-RV & GGCTAGCACTAGTGTAAGCTTCAGCCTCTCTITTCTCG \\
\hline Pc12g07500 Spe1-FW & CGTTAGACTAGTGCCCCAGCTCTCGATTCAGAGC \\
\hline \multicolumn{2}{|l|}{ Expression (RT-qPCR) } \\
\hline Pc12g07500 $208 \mathrm{FW}$ & TCCGGGTACCTTGACTGTGC \\
\hline Pc12g07500 208 RW & CCCGAGCCACCTTGAAAGAC \\
\hline Pc12g07500 209 FW & TCCGGGTACCTTGACTGTGC \\
\hline Pc12g07500 209 RV & CCCGAGCCACCTTGAAAGAC \\
\hline Pc12g13330 210 FW & GACGCTTTGCAACCAGAAGG \\
\hline Pc12g13330 210 RV & TGGGACGGTACCCAAAGATG \\
\hline 3' FW ACT1 & GGCTTCTTTGACTACCTTCCA \\
\hline 3' RV ACT1 & AGAAACACTTGTGGTGAACGA \\
\hline
\end{tabular}


XhoI (downstream) were introduced in the synthetic gene. The synthetic gene and p426GPD [44] were restricted with SpeI and XhoI and fragments were recovered from agarose gels with a commercial kit (Zymoclean, Zymo Research). The synthetic gene was ligated into $\mathrm{SpeI} / \mathrm{Xhol}$ digested p426GPD, resulting in plasmid pUDE250. The expression vector pUDE250 carries Pc12g13330 cDNA placed under the control of the TDH3 promoter.

Transformations of recombination reaction products into competent E. coli JM109 were performed with the Z-Competent E. coli transformation kit (Zymo Research, Orange, CA) and plated on LB media containing either ampicillin $\left(100 \mathrm{mg} \mathrm{l}^{-1}\right)$ or kanamycin $\left(50 \mathrm{mg} \mathrm{l}^{-1}\right)$. The gene sequences in entry clone pUD254 and pUD288 were checked by restriction digestion and DNA sequencing performed at BaseClear, BV (Leiden, The Netherlands).

Plasmids pUDE230, pUDE249, pUDE250 and the URA3bearing 'empty vector' plasmid p426GPD [44] were transformed into S. cerevisiae CEN.PK113-5D using the lithium acetate protocol [70]. After transformations with the yeast expression plasmid, cells were plated on chemically defined medium. Successful insertion of multicopy plasmids was verified by diagnostic PCR using the primer pairs used for PCR amplification. S. cerevisiae CEN.PK113-5D containing plasmids pUDE230, pUDE249, pUDE250 and p426GPD were designated as IME208, IME209, IME210 and IME211 respectively (Table 3).

\section{Quantitative real time PCR (RT-qPCR)}

For preparation of cDNA for RT-qPCR, synthesis of firststand cDNA was carried out using a QuantiTect reverse transcription kit (Qiagen, Venlo, Netherlands). Total RNA was isolated from shake flasks of $S$. cerevisiae strains IME208, IME 209 and IME 210 according to the manufacturer's recommendations. Primers for real-time PCR (Table 4) were designed with Clone Manager 9 (Scientific \& Educational Software, Cary, NC). Basic Local Alignment Search Tool (BLAST) [71] analysis was used to verify that each primer pair was specific for a particular $P$. chrysogenum gene, and would not cross-react with the S. cerevisiae genome. RT-qPCR assays were carried out using SYBR $^{\circ}$ Green Jumpstart ${ }^{\mathrm{mi}}$ Taq ReadyMix ${ }^{\mathrm{mm}}$ (Sigma-Aldrich, St. Louis, MO) in the DNA Engine Opticon ${ }^{\text {Tw }}$ I system from MJ research ${ }^{\mathrm{Tx}}$ according to the manufacturer's instructions. PCR reactions on cDNA template were carried out in triplicate. The results for each growth condition were derived from two independently cultured replicates. Data were analyzed using the Opticon Monitor ${ }^{\text {Twx }}$ software package version 1.04, calculating Ct values. Melting curves were used to monitor the specificity of the reaction. $\beta$ Actin (ACT1) was used as an internal control for sample normalization. PCR reactions on each sample were conducted in triplicate. Data were analyzed by the comparative threshold cycle method [72].

\section{Additional file}

Additional file 1: Table S1. K-mean clustered gene expression profiles over the course of co-cultivation of $P$. chrysogenum with $B$. subtilis. The numerical data represent the average of the normalized hybridization data.

\section{Competing interests}

The authors declare that they have no competing interests.

\section{Authors' contributions}

JTP and J-MD designed the study. IB, TV, DVD performed the experiments. IB, TV, DVD, JTP and J-M Daran performed the data analysis and prepared the manuscript. All authors read and approved the final manuscript.

\section{Acknowledgements}

This project was part of the research programme of the Kluyver Centre for Genomics of Industrial Fermentation, which was sponsored by the Netherlands Genomics Initiative. We are grateful to Prof. Malgorzata Pleszczynska, Maria Curie-Sklodowska University, Lublin, Poland for providing mutan samples.

\section{Author details}

'Department of Biotechnology, Delft University of Technology, Julianalaan 67, 2628 BC Delft, the Netherlands. ${ }^{2}$ Kluyver Centre for Genomics of Industrial Fermentation, Julianalaan 67, 2628 BC Delft, the Netherlands. ${ }^{3}$ Platform for Green Synthetic Biology, P.O. Box 5057, 2600 GA Delft, the Netherlands.

Received: 23 January 2014 Accepted: 17 April 2014

Published: 6 May 2014

\section{References}

1. Thykaer J, Nielsen J: Metabolic engineering of beta-lactam production. Metab Eng 2003, 5:56-69.

2. van den Berg MA, Albang R, Albermann K, Badger JH, Daran JM, Driessen AJM, Estrada CG, Fedorova ND, Harris D, Heijne W, Joardar V, Kiel J, Kovalchuk A, Martin JF, Niermann WC, Nijland JG, Pronk JT, Roubos JA, van der Klie I, Van Peij NNME, Veenhuis M, Von Dohren H, Wagner C, Wortman J, Bovenberg RAL: Genome sequencing and analysis of the filamentous fungus Penicillium chrysogenum. Nat Biotechnol 2008, 26:1161-1168.

3. Ali H, Ries MI, Nijland JG, Lankhorst PP, Hankemeier T, Bovenberg RA, Vreeken RJ, Driessen AJ: A branched biosynthetic pathway is involved in production of roquefortine and related compounds in Penicillium chrysogenum. PLOS ONE 2013, 8:e65328.

4. Ries Ml, Ali H, Lankhorst PP, Hankemeier T, Bovenberg RA, Driessen AJ, Vreeken RJ: Novel Key Metabolites Reveal Further Branching of the Roquefortine/Meleagrin Biosynthetic Pathway. J Biol Chem 2013, 288:37289-37295

5. Harris DM, van der Krogt ZA, Klaassen P, Raamsdonk LM, Hage S, van den Berg MA, Bovenberg RA, Pronk JT, Daran JM: Exploring and dissecting genome-wide gene expression responses of Penicillium chrysogenum to phenylacetic acid consumption and penicilling production. BMC Genomics 2009, 10:75.

6. Harris DM, Westerlaken I, Schipper D, van der Krogt ZA, Gombert AK Sutherland J, Raamsdonk LM, van den Berg MA, Bovenberg RA, Pronk JT, Daran JM: Engineering of Penicillium chrysogenum for fermentative production of a novel carbamoylated cephem antibiotic precursor. Metab Eng 2009, 11:125-137.

7. Douma RD, Batista JM, Touw KM, Kiel JA, Krikken AM, Zhao Z, Veiga T, Klaassen P, Bovenberg RA, Daran JM, Heijnen JJ, Van Gulik WM: Degeneration of penicillin production in ethanol-limited chemostat cultivations of Penicillium chrysogenum: A systems biology approach. BMC Syst Biol 2011, 5:132

8. Veiga T, Gombert AK, Landes N, Verhoeven MD, Kiel JA, Krikken AM, Nijland JG, Touw H, Luttik MA, van der Toorn JC, Driessen AJ, Bovenberg RA, van den Berg MA, van der Klei IJ, Pronk JT, Daran JM: Metabolic engineering of beta-oxidation in Penicillium chrysogenum for improved semi-synthetic cephalosporin biosynthesis. Metab Eng 2012, 14:437-448.

9. Veiga T, Nijland JG, Driessen AJ, Bovenberg RA, Touw H, van den Berg MA, Pronk JT, Daran JM: Impact of velvet complex on transcriptome and 
penicillin $\mathrm{G}$ production in glucose-limited chemostat cultures of a betalactam high-producing Penicillium chrysogenum strain. OMICS 2012, 16:320-333.

10. Veiga T, Solis-Escalante D, Romagnoli G, Ten PA, Hanemaaijer M, Deshmukh AT, Wahl A, Pronk JT, Daran JM: Resolving phenylalanine metabolism sheds light on natural synthesis of penicillin $\mathrm{G}$ in Penicillium chrysogenum. Eukaryot Cell 2012, 11:238-249.

11. Firn RD, Jones CG: The evolution of secondary metabolism - a unifying model. Mol Microbiol 2000, 37:989-994.

12. Goh EB, Yim G, Tsui W, McClure J, Surette MG, Davies J: Transcriptional modulation of bacterial gene expression by subinhibitory concentrations of antibiotics. Proc Natl Acad Sci U S A 2002, 99:17025-17030.

13. Yin J, Straight PD, Hrvatin S, Dorrestein PC, Bumpus SB, Jao C, Kelleher NL, Kolter $\mathrm{R}$, Walsh $\mathrm{CT}$ : Genome-wide high-throughput mining of natural-product biosynthetic gene clusters by phage display. Chem Biol 2007, 14:303-312.

14. Aminov Rl: The role of antibiotics and antibiotic resistance in nature. Environ Microbiol 2009, 11:2970-2988.

15. Brakhage AA, Schroeckh V: Fungal secondary metabolites - strategies to activate silent gene clusters. Fungal Genet Biol 2011, 48:15-22.

16. Chiang YM, Szewczyk E, Nayak T, Davidson AD, Sanchez JF, Lo HC, Ho WY, Simityan H, Kuo E, Praseuth A, Watanabe K, Oakley BR, Wang CC: Molecular genetic mining of the Aspergillus secondary metabolome: discovery of the emericellamide biosynthetic pathway. Chem Biol 2008, 15:527-532.

17. Corre C, Song L, O'Rourke S, Chater KF, Challis GL: 2-Alkyl-4hydroxymethylfuran-3-carboxylic acids, antibiotic production inducers discovered by Streptomyces coelicolor genome mining. Proc Natl Acad SC US A 2008, 105:17510-17515.

18. Schroeckh V, Scherlach K, Nutzmann HW, Shelest E, Schmidt-Heck W, Schuemann J, Martin K, Hertweck C, Brakhage AA: Intimate bacterial-fungal interaction triggers biosynthesis of archetypal polyketides in Aspergillus nidulans. Proc Natl Acad Sci U S A 2009, 106:14558-14563.

19. Dennis $P$, Edwards EA, Liss SN, Fulthorpe R: Monitoring gene expression in mixed microbial communities by using DNA microarrays. Appl Environ Microbiol 2003, 69:769-778.

20. Even S, Charlier C, Nouaille S, Ben Zakour NL, Cretenet M, Cousin FJ, Gautier $M$, Cocaign-Bousquet M, Loubiere P, Le LY: Staphylococcus aureus virulence expression is impaired by Lactococcus lactis in mixed cultures. Appl Environ Microbiol 2009, 75:4459-4472

21. Nouaille S, Even S, Charlier C, Le LY, Cocaign-Bousquet M, Loubiere P: Transcriptomic response of Lactococcus lactis in mixed culture with Staphylococcus aureus. Appl Environ Microbiol 2009, 75:4473-4482.

22. Mendes F, Sieuwerts S, De HE, Almering MJ, Luttik MA, Pronk JT, Smid EJ, Bron PA, Daran-Lapujade P: Transcriptome-based characterization of interactions between Saccharomyces cerevisiae and Lactobacillus delbrueckii subsp. bulgaricus in lactose-grown chemostat cocultures. Appl Environ Microbiol 2013, 79:5949-5961

23. Romero D, De VA, Rakotoaly RH, Dufour SE, Veening JW, Arrebola E, Cazorla FM, Kuipers OP, Paquot M, Perez-Garcia A: The iturin and fengycin families of lipopeptides are key factors in antagonism of Bacillus subtilis toward Podosphaera fusca. Mol Plant Microbe Interact 2007, 20:430-440.

24. Bar-Joseph Z: Analyzing time series gene expression data. Bioinformatics 2004, 20:2493-2503.

25. Gasch AP, Spellman PT, Kao CM, Carmel-Harel O, Eisen MB, Storz G, Botstein $D$, Brown PO: Genomic expression programs in the response of yeast cells to environmental changes. Mol Biol Cell 2000, 11:4241-4257.

26. Nantel A, Dignard D, Bachewich C, Harcus D, Marcil A, Bouin AP, Sensen CW, Hogues H, Het HM V, Gordon P, Rigby T, Benoit F, Tessier DC, Thomas DY, Whiteway M: Transcription profiling of Candida albicans cells undergoing the yeast-to-hyphal transition. Mol Biol Cell 2002, 13:3452-3465

27. Kresnowati MT, Van Winden WA, Almering MJ, Ten Pierick A, Ras C, Knijnenburg TA, Daran-Lapujade P, Pronk JT, Heijnen JJ, Daran JM: When transcriptome meets metabolome: fast cellular responses of yeast to sudden relief of glucose limitation. Mol Syst Biol 2006, 2:49.

28. Ronen M, Botstein D: Transcriptional response of steady-state yeast cultures to transient perturbations in carbon source. Proc Natl Acad SC U S A 2006, 103:389-394.

29. Twumasi-Boateng K, Yu Y, Chen D, Gravelat FN, Nierman WC, Sheppard DC: Transcriptional profiling identifies a role for BrlA in the response to nitrogen depletion and for StuA in the regulation of secondary metabolite clusters in Aspergillus fumigatus. Eukaryot Cell 2009, 8:104-115.
30. Fleming A: On the antibacterial action of cultures of a Penicillium, with special reference to their use in the isolation of $B$. influenza. Exp Pathol 1929, 10:226-236.

31. Newbert RW, Barton B, Greaves P, Harper J, Turner G: Analysis of a commercially improved Penicillium chrysogenum strain series: involvement of recombinogenic regions in amplification and deletion of the penicillin biosynthesis gene cluster. J Ind Microbiol Biotechnol 1997 19:18-27.

32. Daran-Lapujade P, Daran JM, Van Maris AJ, De Winde JH, Pronk JT: Chemostat-based micro-array analysis in baker's yeast. Adv Microb Physiol 2009, 54:257-311.

33. Tusher VG, Tibshirani R, Chu G: Significance analysis of microarrays applied to the ionizing radiation response. Proc Natl Acad Sci U S A 2001 98:5116-5121.

34. Barredo JL, Diez B, Alvarez E, Martin JF: Large amplification of a 35-kb DNA fragment carrying two penicillin biosynthetic genes in high penicillin producing strains of Penicillium chrysogenum. Curr Genet 1989, 16:453-459.

35. Gutierrez S, Fierro F, Casqueiro J, Martin JF: Gene organization and plasticity of the beta-lactam genes in different filamentous fungi. Antonie Van Leeuwenhoek 1999, 75:81-94.

36. Rodriguez-Saiz M, Barredo JL, Moreno MA, Fernandez-Canon JM, Penalva MA, Diez B: Reduced function of a phenylacetate-oxidizing cytochrome p450 caused strong genetic improvement in early phylogeny of penicillin-producing strains. J Bacterio/ 2001, 183:5465-5471.

37. Rodriguez-Saiz M, Diez B, Barredo JL: Why did the Fleming strain fail in penicillin industry? Fungal Genet Biol 2005, 42:464-470

38. Garcia-Estrada C, Ullan RV, Albillos SM, Fernandez-Bodega MA, Durek P, Von DH, Martin JF: A single cluster of coregulated genes encodes the biosynthesis of the mycotoxins roquefortine $C$ and meleagrin in Penicillium chrysogenum. Chem Biol 2011, 18:1499-1512.

39. Hidalgo PI, Ullan RV, Albillos SM, Montero O, Fernandez-Bodega MA, GarciaEstrada C, Fernandez-Aguado M, Martin JF: Molecular characterization of the PR-toxin gene cluster in Penicillium roqueforti and Penicillium chrysogenum: Cross talk of secondary metabolite pathways. Fungal Genet Biol 2014, 62:11-24.

40. Kroken S, Glass NL, Taylor JW, Yoder OC, Turgeon BG: Phylogenomic analysis of type I polyketide synthase genes in pathogenic and saprobic ascomycetes. Proc Natl Acad Sci U S A 2003, 100:15670-15675.

41. Baker SE, Kroken S, Inderbitzin P, Asvarak T, Li BY, Shi L, Yoder OC, Turgeon BG: Two polyketide synthase-encoding genes are required for biosynthesis of the polyketide virulence factor, T-toxin, by Cochliobolus heterostrophus. Mol Plant Microbe Interact 2006, 19:139-149.

42. Fuglsang CC, Berka RM, Wahleithner JA, Kauppinen S, Shuster JR, Rasmussen G, Halkier T, Dalboge H, Henrissat B: Biochemical analysis of recombinant fungal mutanases. A new family of alpha1,3-glucanases with novel carbohydratebinding domains. J Bio/ Chem 2000, 275:2009-2018.

43. Alberti S, Gitler AD, Lindquist S: A suite of Gateway cloning vectors for high-throughput genetic analysis in Saccharomyces cerevisiae. Yeast 2007, 24:913-919.

44. Mumberg D, Muller R, Funk M: Yeast vectors for the controlled expression of heterologous proteins in different genetic backgrounds. Gene 1995, 156:119-122.

45. Bitter GA, Chen KK, Banks AR, Lai PH: Secretion of foreign proteins from Saccharomyces cerevisiae directed by alpha-factor gene fusions. Proc Natl Acad Sci U S A 1984, 81:5330-5334.

46. Button DK: Nutrient-limited microbial growth kinetics: overview and recent advances. Antonie Van Leeuwenhoek 1993, 63:225-235.

47. Vanlerberghe GC, Mclntosh L: Alternative oxidase: From Gene to Function. Annu Rev Plant Physiol Plant Mol Biol 1997, 48:703-734.

48. Zhang L, Oh Y, Li H, Baldwin IT, Galis I: Alternative oxidase in resistance to biotic stresses: Nicotiana attenuata AOX contributes to resistance to a pathogen and a piercing-sucking insect but not Manduca sexta larvae. Plant Physiol 2012, 160:1453-1467.

49. Magnani T, Soriani FM, Martins VP, Policarpo AC, Sorgi CA, Faccioli LH, Curt C, Uyemura SA: Silencing of mitochondrial alternative oxidase gene of Aspergillus fumigatus enhances reactive oxygen species production and killing of the fungus by macrophages. J Bioenerg Biomembr 2008, 40:631-636.

50. Ruiz OH, Gonzalez A, Almeida AJ, Tamayo D, Garcia AM, Restrepo A, McEwen JG: Alternative oxidase mediates pathogen resistance in Paracoccidioides brasiliensis infection. PLoS Negl Trop Dis 2011, 5:e1353. 
51. Akhter S, McDade HC, Gorlach JM, Heinrich G, Cox GM, Perfect JR: Role of alternative oxidase gene in pathogenesis of Cryptococcus neoformans. Infect Immun 2003, 71:5794-5802

52. Quivey RG Jr, Kriger PS: Raffinose-induced mutanase production from Trichoderma harzianum. FEMS Microbiol Lett 1993, 112:307-312.

53. Guggenheim B, Muhlemann H: Mutanase. USA: United States Patent; 1982 $(4,353,891)$.

54. Wiater A, Pleszczynska M, Rogalski J, Szajnecka L, Szczodrak J: Purification and properties of an alpha-(1 $\rightarrow 3$ )-glucanase (EC 3.2.1.84) from Trichoderma harzianum and its use for reduction of artificial dental plaque accumulation. Acta Biochim Pol 2013, 60:123-128.

55. Pleszczynska M, Wiater A, Szczodrak J: Methods for obtaining active mutanase preparations from Paenibacillus curdlanolyticus. Prep Biochem Biotechnol 2008, 38:389-396.

56. Begun J, Gaiani JM, Rohde H, Mack D, Calderwood SB, Ausubel FM, Sifri CD: Staphylococcal biofilm exopolysaccharide protects against Caenorhabditis elegans immune defenses. PLoS Pathog 2007, 3:e57.

57. Shalom G, Pratten J, Wilson M, Nair SP: Cloning, heterologous gene expression and biochemical characterization of the alpha-1,3-glucanase from the filamentous fungus Penicillium purpurogenum. Protein Expr Purif 2008, 60:170-175.

58. Choma A, Wiater A, Komaniecka I, Paduch R, Pleszczynska M, Szczodrak J: Chemical characterization of a water insoluble $(1 \rightarrow 3)$-alpha-D-glucan from an alkaline extract of Aspergillus wentii. Carbohydr Polym 2013, 91:603-608.

59. Sugawara T, Sato M, Takagi T, Kamasaki T, Ohno N, Osumi M: In situ localization of cell wall alpha-1,3-glucan in the fission yeast Schizosaccharomyces pombe. J Electron Microsc (Tokyo) 2003, 52:237-242.

60. Entian KD, Kotter P: Yeast genetic strain and plasmid collections. Method Microbiol 2007, 36:629-666.

61. Nijkamp JF, Van den Broek M, Datema E, De KS, Bosman L, Luttik MA, Daran-Lapujade P, Vongsangnak W, Nielsen J, Heijne WH, Klaassen P, Paddon CJ, Platt D, Kotter P, Van Ham RC, Reinders MJ, Pronk JT, De RD, Daran JM: De novo sequencing, assembly and analysis of the genome of the laboratory strain Saccharomyces cerevisiae CEN.PK113-7D, a model for modern industrial biotechnology. Microb Cell Fact 2012, 11:36. doi:10.1186/1475-2859-11-36.

62. Harris DM, Diderich JA, van der Krogt ZA, Luttik MA, Van Gulik WM, Van Dijken JP, Pronk JT: Enzymic analysis of NADPH metabolism in Penicillium chrysogenum: presence of a mitochondrial NADPH dehydrogenase in beta-lactam-producing cultures. Metab Eng 2006, 8:91-101.

63. Van Gulik WM, Antoniewicz MR, De Laat WT, Vinke JL, Heijnen JJ: Energetics of growth and penicillin production in a high-producing strain of Penicillium chrysogenum. Biotechnol Bioeng 2001, 72:185-193.

64. Nelson N: A photomtric adaptation of the Somogyi method for the determination of glucose. J Biol Chem 1944, 153:375-380.

65. Hazelwood LA, Walsh MC, Luttik MA, Daran-Lapujade P, Pronk JT, Daran JM: Identity of the growth-limiting nutrient strongly affects storage carbohydrate accumulation in anaerobic chemostat cultures of Saccharomyces cerevisiae. Appl Environ Microbiol 2009, 75:6876-6885.

66. Knijnenburg TA, Daran JM, van den Broek MA, Daran-Lapujade PA, De Winde JH, Pronk JT, Reinders MJ, Wessels LF: Combinatorial effects of environmental parameters on transcriptional regulation in Saccharomyces cerevisiae: a quantitative analysis of a compendium of chemostat-based transcriptome data. BMC Genomics 2009, 10:53.

67. Romagnoli G, Luttik MA, Kotter P, Pronk JT, Daran JM: Substrate specificity of thiamine pyrophosphate-dependent 2-oxo-acid decarboxylases in Saccharomyces cerevisiae. Appl Environ Microbiol 2012, 78:7538-7548.

68. An Y, Wu W, LV A: A PCR-after-ligation method for cloning of multiple DNA inserts. Anal Biochem 2010, 402:203-205.

69. Grote A, Hiller K, Scheer M, Munch R, Nortemann B, Hempel DC, Jahn D: JCat: a novel tool to adapt codon usage of a target gene to its potential expression host. Nucleic Acids Res 2005, 33:W526-W531.
70. Gietz RD, Schiestl RH: High-efficiency yeast transformation using the LiAc/ SS carrier DNA/PEG method. Nat Protoc 2007, 2:31-34.

71. Altschul SF, Gish W, Miller W, Myers EW, Lipman DJ: Basic local alignment search tool. J Mol Biol 1990, 215:403-410.

72. Schmittgen TD, Livak KJ: Analyzing real-time PCR data by the comparative C(T) method. Nat Protoc 2008, 3:1101-1108.

doi:10.1186/1471-2180-14-114

Cite this article as: Bajaj et al:: Functional characterization of a Penicillium chrysogenum mutanase gene induced upon co-cultivation with Bacillus subtilis. BMC Microbiology 2014 14:114.

\section{Submit your next manuscript to BioMed Central and take full advantage of:}

- Convenient online submission

- Thorough peer review

- No space constraints or color figure charges

- Immediate publication on acceptance

- Inclusion in PubMed, CAS, Scopus and Google Scholar

- Research which is freely available for redistribution

Submit your manuscript at www.biomedcentral.com/submit
C BioMed Central 